\title{
Die Kommunikation zwischen preußischen Soldaten und Offizieren im Siebenjährigen Krieg zwischen Gewalt und Konsens ${ }^{1}$
}

\section{Einseitige Kommunikation durch Gewalt oder professionelle Suche nach gemeinsamen Interessen?}

Der Schweizer Ulrich Bräker schreibt über seine Gefühle beim Beginn der Schlacht bei Lobositz am 1. Oktober 1756, an der er als preußischer Musketier teilnehmen mußte: "Da fiel mir vollends aller Muth in die Hosen²; in den Bauch der Erde hätt' ich mich verkriechen mögen, und eine ähnliche Angst, ja Todesblässe, las' man bald auf allen Gesichtern ${ }^{3}$.« Bräkers Empfindungen waren nichts Ungewöhnliches ${ }^{4}$. Auch das preußische Oberkommando war sich der Tatsache bewußt, daß die Angst vor Tod und Verstümmelung aus den wohlgeordneten Bataillonen und Regimentern binnen Sekunden einen »konfusen Klumpen $\aleph^{5}$ machen konnte. In den »Ordres, wenn die Armee mit dem Feinde Bataillren [sic! eigentlich »batailliren«: eine Schlacht liefern] soll « findet sich im Reglement von 1743 die Anweisung: "Die Officiers und Unter-Officiers müssen die Leute immer encouragiren [ermutigen], ihnen die Sache gantz leichte machen, und, wenn jemand zu weichen anfangen wollte, selbigem den Degen, Sponton oder Kurz-Gewehr in die Rippen stossen ${ }^{6}$. « Diese Anordnung findet sich auch in österreichischen Vorschriften von 1741 und $1749^{7}$

1 Meiner Frau, Cornelia Habisch, habe ich für die Durchsicht und wertvolle Hinweise zu danken, meiner Tochter für ihre Geduld und meinen Eltern für ihre Hilfsbereitschaft. Mein Dank gilt auch Frau Dr. habil. Jutta Nowosadtko und Herrn Dr. des. Martin Winter für viele Diskussionen zum Militärwesen im Ancien régime.

2 Eventuell deutet Bräker hier ein Phänomen an, von dem viele moderne Soldaten berichten: das Erschlaffen der Därme aus Todesangst. Vgl. Paul Fussell, Wartime. Understanding and Behavior in the Second World War, New York, Oxford, 1989, S. 277 f.

3 Ulrich Bräker, Das Leben und die Abentheuer des Armen Mannes im Tockenburg. Mit einem Beitr. von Helmut Eckert. Neudr. der Ausg. Zürịch 1788, Osnabrück 1980, S. 151 f.

4 Sascha Möbius, »Von Jast und Hitze wie vertaumelt«. Überlegungen zur Wahrnehmung von Gewalt durch preußische Soldaten im Siebenjährigen Krieg, in: Forschungen zur Brandenburgischen und Preußischen Geschichte, N.F., 12 (2002), 1, S. 33. Zum Teil alternativ: Martin Dinges, Soldatenkörper in der Frühen Neuzeit. Erfahrungen mit einem unzureichend geschützten, formierten und verletztem Körper in Selbstzeugnissen, in: Körper-Geschichten. Hrsg. von Richard van Dülmen, Frankfurt a.M. 1996 (= Studien zur historischen Kulturforschung, 5), S. 88 f.

5 Hans Karl von Winterfeldt, "Relation von der Bataille bei Prag in Ansehung der Infanterie. Im Lager bei Prag den 8. Mai 1757«, in: August von Janson, Hans Karl von Winterfeldt, des Großen Königs Generalstabschef, Berlin 1913, S. 436.

6 Reglement vor die Königl. Preußische Infanterie von 1726, Faks.Dr. der Ausg. [Potsdam] 1726, Osnabrück 1968, S. 361; Reglement für die Königl. Preußische Infanterie, Faks.Dr. der Ausg. Berlin 1743, Osnabrück 1976, S. 347.

7 Alexander Balisch, Die Entstehung des Exerzierreglements von 1749. Ein Kapitel der Militärreform von 1748/49, in: Mitteilungen des Österreichischen Staatsarchivs, 27 (1974), S. 181. 
und gehörte im 18. Jahrhundert »zum militärischen Allgemeingut « ${ }^{8}$. So klingt der Satz Friedrichs II., daß »der gemeine Soldat vor dem Officiere mehr Furcht als vor dem Feinde haben [soll] " $"$, denn auch wie ein Kommentar zu der entsprechenden Stelle im preußischen Reglement.

Die borussophile Literatur des 19. und frühen 20. Jahrhunderts behandelt das Gewaltverhältnis ${ }^{10}$ zwischen Soldaten und Offizieren nicht ${ }^{11}$ oder nur am Rande und betont vor allem den von ihr angenommenen Patriotismus ${ }^{12}$ und die Königstreue der Soldaten aus den brandenburgischen Kernprovinzen sowie deren Vertrauen auf die eigene Ausbildung ${ }^{13}$. Im Gegensatz dazu hebt die moderne Forschung hervor, daß die Kommunikation zwischen Soldaten und Offizieren auf dem Schlachtfeld einseitig war und im wesentlichen auf Zwang, Gewaltandrohung und -ausübung beruhte ${ }^{14}$. Michael Sikora weist auch auf die Bedeutung der Disziplinierung hin ${ }^{15}$. Er schränkt die Bedeutung dieses Aspektes aber ein: $\gg \mathrm{Ob}$ allerdings Zwang und Angst tatsächlich ausreichten, ein Heer erfolgreich ins Gefecht zu führen, erscheint zweifelhaft. [...] Ob aber die Soldaten tatsächlich die ganze Zeit nur den Offizier im Genick gespürt haben ${ }^{16}$ ? « Dabei hebt er die "kaum zu überschätzende Bedeutung ${ }^{17}$ der Religion in Form eines »Schicksalsglaubens ${ }^{18}$ hervor.

Vgl. vor allem Michael Sikora, Disziplin und Desertion: Strukturprobleme militärischer Organisation im 18. Jahrhundert, Berlin 1996 (= Historische Forschungen, 57), S. 165; Christopher Duffy, The Military Experience in the Age of Reason, London 1998, S. 220.

9 Ulrich Bröckling, Disziplin. Soziologie und Geschichte militärischer Gehorsamsproduktion, München 1997, S. 73.

10 Gewalt im Sinne von körperlichem Zwang zur Durchsetzung herrschaftlicher Anordnungen. Zum Gewaltbegriff in der Frühen Neuzeit vgl. Ralf Pröve, Violentia und Potestas. Perzeptionsprobleme von Gewalt in Söldnertagebüchern des 17. Jahrhunderts, in: Ein Schauplatz herber Angst. Wahrnehmung und Darstellung von Gewalt im 17. Jahrhundert. Hrsg. von Markus Meumann und Dirk Niefanger, Göttingen 1997, S. 32-35. Ralf Pröve, Gewalt und Herrschaft in der Frühen Neuzeit. Formen und Formenwandel von Gewalt, in: Zeitschrift für Geschichtswissenschaft, 47 (1999), S. 792-806.

11 Curt Jany, Geschichte der Preußischen Armee, Bd 2, Osnabrück 1967, S. 304-309.

12 Ein Autor des Generalstabs sieht in den von ihm veröffentlichten Soldatenbriefen gar die »deutsche Berufung Preußens«. Briefe preußischer Soldaten aus den Feldzügen 1756 und 1757 und über die Schlächten bei Lobositz und Prag. Hrsg. vom Großen Generalstab, Berlin 1901, S. VI.

13 Jany, Geschichte der Preußischen Armee (wie Anm. 11), S. 243 f. Die Kriege Friedrichs des Großen. Hrsg. vom Großen Generalstab, Kriegsgeschichtliche Abtheilung 2, Theil 3: Der Siebenjährige Krieg, Bd 2, S. 139.

14 Vgl. Sikora, Disziplin (wie Anm. 8), S. 176; Johannes Kunisch, Das »Puppenwerk» der stehenden Heere. Ein Beitrag zur Neueinschätzung von Soldatenstand und Krieg in der Spätaufklärung, in: Johannes Kunisch, Fürst - Gesellschaft - Krieg. Studien zur bellizistischen Disposition des absoluten Fürstenstaates, Köln [u.a.] 1992, S. 181 f.; Frank Wernitz, Die preußischen Freitruppen im Siebenjährigen Krieg 1756-1763. Entstehung - Einsatz - Wirkung, Wölfersheim-Berstadt 1994, S. 7; Otto Büsch, Militärsystem und Sozialleben im alten Preußen 1713-1807. Die Anfänge der sozialen Militarisierung der preußischdeutschen Gesellschaft, Frankfurt a.M. [u.a.] 1981, S. 43; Bröckling, Disziplin (wie Anm. 9), S. 66; Olaf Groehler, Die Kriege Friedrichs II., 4. Aufl., Berlin (Ost) 1986, S. 169; Christopher Duffy, Friedrich der Große und seine Armee, Stuttgart 1978, S. 237. Duffy dehnt diese Analyse aber nicht allgemein auf die Armeen des Ancien régime aus. Vgl. Christopher Duffy, The Military Experience (wie Anm. 8), S. 82-84.

15 Sikora, Disziplin (wie Anm. 8), S. 165-167.

16 Ebd., S. 167.

17 Ebd., S. 281.

18 Ebd., S. 284. 
Zu einer anderen Einschätzung kommt der amerikanische Militärhistoriker Dennis Showalter. Er unterstreicht die militärische Kompetenz und Siegeszuversicht, die sich in einer Überlebensstrategie bündeln: "The most effective survival mechanism in battle was to stand one's ground and keep fighting ${ }^{19}$. . Auch deuten neueste Forschungen zur Kommunikation in Brandenburg-Preußen in eine andere Richtung. Ralf Pröves Zusammenfassung bezüglich der staatlichen Kommunikation ist für diesen Beitrag richtungweisend:

"Die moderne historische Kommunikationsforschung folgt einem erweiterten

Kommunikationsbegriff. Dieser sieht in den Empfängern medialer Botschaften nicht nur passive Rezipienten. Vielmehr gelten Zuschauer, Hörer oder Leser als handelnd und aktiv, indem sie zur Verfügung gestellte Informationen interpretieren und mit eigenen Zielen und Wertsetzungen versehen - und schließslich ihre weiteren Handlungen und Aktionen danach gestalten ${ }^{20}$.«

Es bleibt die Frage, ob die Kommunikation zwischen Offizieren und Soldaten im Kampf vor allem einseitig und von Gewaltanwendung geprägt war. Eine Annäherung an das Thema erfordert zunächst die Untersuchung der Ausbildung anhand von Reglements und Berichten. Im Kampfgeschehen stehen aufgrund der Überlieferungslage die Zurufe von Offizieren an ihre Soldaten im Mittelpunkt, die sich in Briefen und Tagebüchern; aber auch militärgeschichtlichen Werken und Tagebüchern von Einheiten finden lassen ${ }^{21}$. Dabei interessieren neben der sprachlichen Kommunikation auch Verhaltensweisen von Offizieren, die dazu dienen sollten, die Angst der eigenen Truppen zu neutralisieren und die Ausführung von Befehlen durchzusetzen.

Die angesprochenen Inhalte der Zurufe müssen mit ermittelbaren Einflüssen auf das Kampfverhalten der Soldaten und ihre Interessenlage verglichen werden, um die Grundlagen einer erfolgreichen (oder mißlungenen) Kommunikation zwischen den verschiedenen Dienstgraden zu ermitteln. Auf seiten der "Gemeinen " ist darüber hinaus zu fragen, wie sie auf die rekonstruierbaren Kommunikationsversuche der Offiziere reagierten. Dies konnte in Form einer sprachlichen Antwort geschehen, aber auch eine "Abstimmung mit den Füßen “ beinhalten.

19 Dennis Showalter, Tactics and Recruitment in Eighteenth Century Prussia, in: Studies in History and Politics / Etudes d'Histoire et de Politique, 3 (1984), S. 20 f. Ähnliche Positionen in der deutschen Forschung: Jürgen Kloosterhuis, Donner, Blitz und Bräker. Der Soldatendienst des "armen Mannes im Tockenburg « aus der Sicht des preußischen Militärsystems, in: Schreibsucht. Autobiographische Schriften des Pietisten Ulrich Bräker (1735-1798). Hrsg. von Alfred Messerli und Adolf Muschg, Göttingen 2004 (= Arbeiten zur Geschichte des Pietismus, 44), S. 172; Jörg Muth, Flucht aus dem militärischen Alltag. Ursachen und individuelle Ausprägung der Desertion in der Armee Friedrichs des Großen, Freiburg i. Br. 2003 (= Einzelschriften zur Militärgeschichte, 42), S. 69 f.; Bernhard R. Kroener, Militär in der Gesellschaft. Aspekte einer neuen Militärgeschichte der Frühen Neuzeit, in: Was ist Militärgeschichte? Hrsg. von Thomas Külnne und Benjamin Ziemann, Paderborn 2000, S. 294.

20 Ralf Pröve, Herrschaft als kommunikativer Prozess: das Beispiel Brandenburg-Preußen, in: Wissen ist Macht. Herrschaft und Kommunikation in Brandenburg-Preußen. 1600-1850. Hrsg. von Ralf Pröve und Norbert Winnige, Berlin 2001, S. 12.

${ }_{21}$ Quellen in: Möbius, »Von Jast und Hitze wie vertaumelt« (wie Anm. 4), S. 3 f., Anm. 15 und 16. 


\section{Die Ausbildung}

Die Grundausbildung der preußischen Infanterie vor dem Siebenjährigen Krieg stützte sich weitgehend auf die unter dem Soldatenkönig, Friedrich Wilhelm I., entwickelten Anweisungen. Sie waren 1726 in einem Reglement zusammengefaßt worden, das die Grundlage der 1743 überarbeiteten Vorschriften bildet ${ }^{22}$, und orientierten sich an der Elementartaktik der niederländischen und britischen Armee im Spanischen Erbfolgekrieg ${ }^{23}$. Die kleinste Einheit, die normalerweise in der Schlacht als »taktischer Körper ${ }^{24}$ eingesetzt wurde und den eigentlichen Kommunikationsraum bildete, war das Bataillon. Es bestand aus fünf Musketier- und einer Grenadierkompanie ${ }^{25}$ :

"25. Ober-Officiers, worunter ein subalterner Officier Adjutant ist.

59. Unter-Officiers.

3. Pfeiffers.

19. Tambours.

126. Grenadiers.

570. Musquetiers ${ }^{26}$ «

Die »Grenadiers « exerzierten zusammen mit den Musketieren, wurden im Kriegsfall aber in Grenadierbataillonen zusammengefaßt ${ }^{27}$. Letztere waren zur Zeit des Soldatenkönigs kleinere, aber belastbare Soldaten ${ }^{28}$ und wurden später vor allem im Kleinkrieg und für besonders heikle Aktionen in der Schlacht gebraucht. Die Musketiere hingegen dienten als Linieninfanterie, konnten aber auch im Kleinen Krieg zum Einsatz kommen ${ }^{29}$.

Dem Rekruten wurde zunächst eine gerade und aufrechte Körperhaltung beigebracht $t^{30}$. Sie war in der eng geschlossenen Formation des Bataillons sinnvoll, da so Unordnung verhindert werden konnte. Auch mochte die Eliminierung einer von Unterwürfigkeit geprägten Haltung den Soldaten furchterregender aussehen lassen $^{31}$ und dazu beitragen, ihm ein Gefühl eigener Stärke zu geben.

Die Grundzüge des Exerzierens wurden dem Soldaten von einem Unteroffizier beigebracht, der angewiesen war, den Rekruten nicht anzubrüllen oder zu schlagen $^{32}$. Die Handgriffe beim Laden und die verschiedenen Bewegungen waren

Brent Nosworthy, Anatomy of Victory. Battle Tactics 1689-1763, New York 1990, S. 5 f

24 Hans Delbrück, Geschichte der Kriegskunst im Rahmen der politischen Geschichte, Bd 4: Neuzeit, Berlin 1962, S. 72.

25 Die Kompanien und Regimenter waren organisatorische Einheiten.

26 Reglement von 1743 (wie Anm. 6), S. 4.

27 Jedes Regiment hatte zwei Grenadierkompanien. Ein Grenadierbataillon bestand aus den Grenadierkompanien von zwei Regimentern

${ }_{28}$ Reglement von 1726 (wie Anm. 6), S. 7 f., S. 18. Das Reglement von 1743 enthält keine Vorschriften zur Auswahl von Grenadieren.

29 Wolfgang Petter, Zur Kriegskunst im Zeitalter Friedrichs des Großen, in: Europa im Zeitalter Friedrichs des Großen. Wirtschaft, Gesellschaft, Kriege. Hrsg. von Bernhard R. Kroener, München 1989, S. 266 f.; Günther Gieraths, Die Kampfhandlungen der brandenburgisch-preußischen Armee, Berlin 1964.

30 Reglement von 1743 (wie Anm. 6), S. 42 f. Vgl. Reglement von 1726 (wie Anm. 6), S. 39 f.

31 Harald Kleinschmidt, Tyrocinium Militare. Militärische Körperhaltungen und -bewegungen im Wandel zwischen dem 14. und dem 18. Jahrhundert, Stuttgart 1989, S. 244.

32 Reglement von 1743 (wie Anm. 6), S. 187. Vgl. Reglement von 1726 (wie Anm. 6), S. 222. 
offenbar nicht sehr schwer. Doch bedurfte es eines guten Lehrers, um sie zu erlernen $^{33}$. War der Rekrut mit dem Grundsätzlichen vertraut, konnte er am gemeinsamen Exerzieren teilnehmen. Das angetretene Bataillon wurde vertikal in acht Pelotons unterteilt. In der Mitte befand sich das Fahnenpeloton, welches die fünf Fahnen des Bataillons absicherte ${ }^{34}$. Offiziere befanden sich sowohl neben den Pelotons als auch hinter der Kampflinie. Die exponierteste Position hatte der Kommandeur. Er befand sich vor dem Fahnenpeloton und mußte die Einheit gut sichtbar zu Pferde anführen ${ }^{35}$.

Die Grundlage der Gefechtsausbildung war das Pelotonfeuer. Hierzu fiel das erste Glied auf das rechte Knie, so daß »das 2te Glied [...] den rechten Fuß vom 1 ten Gliede zwischen den Beinen " hat. "Das 3te Glied hingegen [muß] in die Lucken vom 2ten Gliede einrücken, darauf woll gesehen werden soll, denn, wann solches nicht geschiehet, die Kerls sich allemahl verbrennen ${ }^{36}$. Die acht Pelotons waren von rechts nach links durchnumeriert. Nr. 1 schoß zuerst, kurz danach Nr. 8, dann Nr. 2, gefolgt von Nr. 7, usw. Das entsprechende Laden, Bereithalten und Feuern wurde von dem das Peloton kommandierenden Hauptmann oder Leutnant einzeln befohlen. Von den Befehlsempfängern erforderte dies schon auf dem Drillplatz ein Höchstmaß an Aufmerksamkeit.

Numerierung der Pelotons: $\quad 87654321$

Reihenfolge beim Feuern: $\quad 24687531^{37}$

Eine weitere preußische Besonderheit war das schon 1705 eingeführte Pelotonfeuer beim Vorrücken ${ }^{38}$. Das gesamte Bataillon mußte in kleinen Schritten "avanciren" [sich auf den Feind zubewegen]. Das Peloton, welches mit dem Schießen an der Reihe war, lief mit drei großen Schritten schnell vor, das erste Glied kniete nieder und das Peloton feuerte. Die der Ausbildung zugrunde liegende Konzeption hat Berenhorst auf den Punkt gebracht: »daß es eigentlich das Feuer sey, aber physisches, mit moralischem verbunden, welches den Sieg zubereite, und daß, man sage, was man wolle, gut schießen, rasch laden, Unerschrockenheit, und muthiger Angriff sicherer zum Ziele führen als - alle Gelehrtheit ${ }^{39}$.

Einige Jahre vor Beginn des Siebenjährigen Krieges kam zur Ausbildung der Angriff mit dem Bajonett hinzu. Die Grundausbildung der Infanterie im Feuerkampf blieb nach der Thronbesteigung Friedrichs II. im Jahre 1740 dieselbe wie im Reglement von 1726 .

»Die hauptsächlichen Neuerungen im Exerzieren betrafen die beim Erscheinen des Reglements von 1726 noch nicht errichteten Grenadierkompagnien, die im Frieden geschlossen auf dem rechten Flügel ihres Bataillons bleiben sollten, im Felde aber ganz von ihren Regimentern getrennt waren [...] Das Bajonett blieb

33 Bräker, Das Leben und die Abentheuer (wie Anm. 3), S. 126.

34 Jede Kompanie hatte eine. Fahne.

35 Vgl. Reglement von 1743 (wie Anm. 6), S. 67 f.

36 Reglement von 1726 (wie Anm. 6), S. 79. Der Hinweis auf das "Verbrennen « fehlt im Reglement von 1743, vgl. Reglement von 1743 (wie Anm. 6), S. 71 f.

37 Ebd., S. 116-124.

38 Balisch, Die Entstehung des Exerzierreglements (wie Anm. 7), S. 174; Reglement von 1743 (wie Anm. 6), S. 124-140.

39 Georg Heinrich von Berenhorst, Betrachtungen über die Kriegskunst. Mit einer Einführung von Eckhard Opitz, Neudr. der 3. Aufl., Leipzig 1827, Osnabrück 1978, S. 54 f. 
beim Exerzieren jetzt stets auf dem Gewehre. [...] Jedem Bataillon sollten beim Ausmarsche zwei Kanonen mit den nötigen Kanonieren zugeteilt werden ${ }^{40}$.« Die Bestimmungen für den Fall einer Schlacht wurden auch verändert. Das Reglement von 1726 spricht bezüglich der Elementartaktik lediglich die Feuerdisziplin an:

"Wie wohl das Chargiren in Action nicht so accurat als wie im Exerciren geschehen kann, jedennoch kein Peloton eher schiessen muß, bis seine Tour kömt, damit die Bataillons in continuirlichem Feuer bleiben, und sich nicht verschiessen können, worauf die sämtliche Officiers zu sehen haben. Auch muß kein Officier eher commandiren zu schiessen, bis der Obriste oder Commandeur vom Bataillon commandiret ${ }^{41}$."

Etwas detaillierter findet sich dieser Passus auch im Reglement von $1743^{42}$. Gänzlich neu hingegen war ein Abschnitt über den Einsatz des Bajonetts:

"Es muß ein jeder Officier, Unter-Officier und Gemeiner sich die feste Impression machen, daß es in der Action auf nichts ankomme, als wie den Feind zu zwingen; von dem Platz, wo er stehet, zu weichen; Deshalb die gantze Gewinnung der Bataille darauf ankommt, daß man nicht sonder Ordre stille stehet, sondern ordentlich und geschlossen gegen den Feind avanciret und chargiret [schießt]; Und weilen die Stärcke der Leute und die gute Ordnung die Preußische Infanterie unüberwindlich machet, so muß den Leuten wohl imprimiret werden, daß, wann der Feind wieder alles Vermuthen stehen bleiben sollte, ihr sicherster und gewissester Vortheil wäre, mit gefällten Bajonets in selbigen herein zu drängen, alsdann der König davor repondiret, daß keiner wieder stechen wird ${ }^{43} \cdot$ *

In den Anweisungen für die Generalmajore der Infanterie von 1748 wurde deutlich hervorgehoben, daßs sich jene Offiziere am meisten »recommendiren « würden, die den Infanterieangriff ohne Gewehrfeuer zustande brächten ${ }^{44}$. Das politische Testament von 1752 erwähnt diese Art des Angriffs gleich an zwei Stellen. Unter dem Stichwort "Rekrutierung « begründet Friedrich II. seinem Nachfolger die preußischen Anforderungen an die Größe der Soldaten: "Diese Größe ist nötig, denn die großgewachsenen Leute sind kräftiger als die anderen. Keine Truppe auf der Welt könnte ihrem Angriff mit aufgepflanztem Bajonett widerstehen ${ }^{45}$ " " Ausführlicher widmet sich Friedrich dieser Thematik einige Absätze später:

"Ich habe sie [die Offiziere] dazu erzogen, im Geschwindschritt auf den Feind loszugehen, ohne zu schießen, nur mit dem Bajonett. Denn man wird den Feind bei kühnem Angriff sicher in die Flucht jagen und viel weniger verlieren als bei langsamem Vorrücken. Eine Schlacht gewinnen, heißt, den Gegner zwingen, Euch seine Stellung zu überlassen. Geht Ihr ihm langsam entgegen, so bringt sein Feuer Euch starke Verluste bei. Rückt Ihr im Geschwindschritt gegen ihn vor,

44 Friedrich II., "Instruction für die General-Majors von der Infanterie«, in: Ausgewählte kriegswissenschaftliche Schriften Friedrichs des Großen. Hrsg. von Heinrich Merkens, Repr. der Ausg. Jena 1876, Braunschweig 1997, S. 163-176.

45 Friedrich II., Das Politische Testament von 1752, in: Friedrich der Große. Hrsg. von Otto Bardong, Darmstadt 1982, S. 239. 
so schont Ihr Eure Soldaten. Eure feste Haltung schlägt ihn und zwingt ihn zur Flucht in Unordnung ${ }^{46}$.

Die alltägliche Ausbildung bestand zwischen dem Zweiten Schlesischen und dem Siebenjährigen Krieg weiterhin vor allem aus dem Einüben der Manöver, Evolutionen und den verschiedenen Arten des Feuerns. Intensivere Übungen des Bajonettangriffs scheinęn erst ab 1755 stattgefunden zu haben ${ }^{47}$. Eine Belehrung von Offizieren fand am 25. August 1755 im Lager bei Spandau statt. Friedrich argumentierte hier offenbar auf zwei Ebenen. Zum einen strich er die »materiellen « Vorteile des Vorgehens mit dem Bajonett heraus, da "man [...] auch weit weniger Leuthe verlieren [würde], wenn man sich nicht mit schießen abgebe, sondern gerade auf den Feind zuginge ${ }^{48}$. Dazu veranstaltete der Monarch einen Versuch mit drei Pelotons von der Garde. Eins stellte den Gegner vor, eins griff mit Feuer im Vorgehen an und das andere mit gefälltem Bajonett. Das Ergebnis faßte Friedrich folgendermaßen zusammen:

"Wenn also auch der Feind nur halb so geschwinde schießet, so bekommt man dennoch 3 mahl mehr Feuer, wenn man sich mit schießen abgiebt als wenn man grade auf den Feind loßgehet, bei den letztren kommt man noch dazu in $1 \mathrm{Mi}-$ nutte 3 mahl weiter von der Stelle als bei der chargirung geschiehet."

Im Nachlaß des Prinzen Moritz von Anhalt-Dessau findet sich eine ähnliche Berechnung. Dabei fällt jedoch auf, daß die Wirkung des eigenen Feuers gar nicht einkalkuliert wird. Es zeigt sich, daß Friedrich hier kein »wissenschaftliches « Experiment durchführen wollte, sondern daß die Übung mehr der Konditionierung der Offiziere (und durch sie der Mannschaften) diente. Zum anderen wird ausdrücklich auf die psychische Dimension dieser Angriffsart verwiesen:

"Durch unser geschwindes avanciren aber setzet man den Burschen in eine Hitze, das er keine Reflexion machet, sondern nur den Feind zu erreichen suchet, weil er weiß daß er alsdann außer Gefahr ist [...] überhaupt durch brusque Attaque wird der muth ungemein verstärkt. Der Feind hingegen wird alle courage und contenance verlihren, wann er sihet daß man ohngeachtet seines starken Feuers auf ihn so dreiste loßgehet ${ }^{49} . "$

46 Ebd., S. 243. Vgl. Friedrich II., "Gedanken und allgemeine Regeln für den Krieg «, in: Militärische Schriften Friedrichs des Großen. Hrsg. von Gustav Berthold Volz, Berlin 1913, S. 91 f. Es scheint sich um verbreitete Ansichten unter Militärs des 18. Jahrhunderts zu handeln. Vgl. Georg Heinrich von Berenhorst, Aus dem Nachlasse. Hrsg. von Eduard von Bülow, Nachdr. der Ausg. Dessau 1845-1847, Osnabrück 1978, S. 135. Vgl. Georg Friedrich von Tempelhof, Geschichte des Siebenjährigen Krieges in Deutschland zwischen dem Könige von Preußen und der Kaiserin Königin mit ihren Alliierten, Neudr. der Ausg. Berlin 1783, Osnabrück 1986, T. 1, S. 66 f.; Johann Gottlieb Tielke, „Von dem Angriff und Vertheidigung der unverschanzten Berge und Anhöhen«, in: Johann Gottlieb Tielke, Beyträge zur Kriegs-Kunst und Geschichte des Krieges von 1756 bis 1763 mit Plans und Charten, 2. Aufl., Freyberg 1776, Stk. I, S. 60-70; Duffy, The Military Experience (wie Anm. 8), S. 204-206.

47 Erste Übungen des Bajonettangriffs fanden 1748 und 1750 statt. Die Taktische Schulung der Preußischen Armee durch König Friedrich den Großen während der Friedenszeit 1745 bis 1756. Hrsg. vom Großen Generalstab, Berlin 1900, S. 445 f.

48 Ebd., S. 446.

49 Ebd., S. 447. Vgl. auch: Carl Frhr. Binder von Kriegelstein, Geist und Stoff im Kriege, T. 1: Das achtzehnte Jahrhundert unter Benutzung handschriftlicher Quellen, Wien, Leipzig 1896, S. 103, Anm. 1. Vgl. "Schreiben eines Königl. Hungarischen Offiziers aus Neiß, vom 14. Apr. 1741 über die Schlacht bey Mollwitz «, in: Sammlung ungedruckter Nachrichten, so die Geschichte der Feldzüge der Preußen von 1740-1779 erläutern, Dresden 1782-1785, T. 1, S. 35. 
Hier zeigt sich eher eine Instrumentalisierung der Gefühle und Interessen der Soldaten als deren Unterdrückung durch Furcht und Gewalt.

Als Kronzeuge für die überragende Bedeutung der Disziplinierung während der Ausbildung wird der König in höchsteigener Person angeführt: "Überhaupt sollte sder gemeine Soldat vor dem Officiere mehr Furcht als vor dem Feinde haben<, da ansonsten niemand im Stande wäre, sihn zum Angriff unter dem Getöse von 300 Kanonen zu führen, welche ihm entgegendonnern ${ }^{50}$." Der Passus kann für den hier untersuchten Zeitraum keine Gültigkeit beanspruchen, denn er stammt aus dem militärischen Testament von $1768^{51}$. Aus dem Kontext geht zudem hervor, daß Friedrich seine Forderung aus den waffentechnischen Veränderungen ableitete:

"Früher war es bei uns Brauch, unsre Regimenter aus möglichst großen Leuten zu bilden. Das geschah nicht ohne Grund; denn in den ersten Kriegen entschieden nicht die Kanonen, sondern die Menschen den Sieg, und Bataillone groß gewachsener Leute, die mit dem Bajonett vorgingen, zerstreuten beim ersten Anlauf die schlecht zusammengesetzten Truppen des Feindes, die sich im Körperwuchs nicht mit den unsren messen konnten. Jetzt hat das Gewehrfeuer alles geändert. Eine Kanonenkugel streckt einen sechs Fuß hohen Mann ebensogut nieder wie einen, der nur fünf Fuß sieben Zoll mißt. Die Kanone macht alles, und die Infanterie kommt nicht mehr zum Kampf mit der blanken Waf$\mathrm{fe}^{52}$.«

So alltäglich das Fluchen, Anbrüllen und Schlagen von Soldaten während der gemeinschaftlichen Ausbildung war, bleibt das Ausmaß der sozialen "Angst vor dem Offizier « umstritten ${ }^{53}$. Auch wird von Militärs festgestellt, daß genau dieser Aspekt der Disziplin während des Krieges zurücktrat ${ }^{54}$. Die wenigen Einschätzungen von Soldaten deuten darauf hin, daß die Ausbildung in erster Linie darauf gerichtet war, die schnelle und präzise Ausführung der Befehle durch sprachlichen Zwang und physische Gewalt sicherzustellen. Wer als letzter sein Gewehr fertig geladen hatte, bekam drei Stockschläge. Ein Offizier konnte von ihm wahrgenommenes Fehlverhalten mit Schlägen bestrafen oder durch einen Unteroffizier bestrafen lassen. Wer sich befehlsgemäß verhielt, konnte damit rechnen, entsprechenden Strafen zu entgehen. Damit spielte die Angst vor Prügeln und Beleidigungen eine wichtige Rolle ${ }^{55}$, doch scheinen entsprechende Strafen zumeist berechenbar geblieben zu sein. Daß diese Grenzen von den Soldaten als verbindlich angesehen wurden, zeigt sich an den sporadisch feststellbaren Widerstandsaktionen ${ }^{56}$. Die Abstufun-

50 Bröckling, Disziplin (wie Anm. 9); S. 73.

51 Friedrich II., Das militärische Testament von 1768, in: Ausgewählte kriegswissenschaftliche Schriften (wie Anm. 44), S. 233.

52 Ebd., S. 232.

53 ' Vgl. Ludwig Matthias von Lossow, Denkwürdigkeiten zur Charakteristik der preußischen Armee unter dem Großen König Friedrich II. Aus dem Nachlasse eines alten preußischen Offiziers, Neudr. der Ausg. Glogau 1826, Neufahrn/Percha 1984, S. 194-229. Martin Winter, Preußisches Kantonsystem und städtische Gesellschaft. Frankfurt an der Oder im ausgehenden 18. Jahrhundert, in: Leben und Arbeiten auf märkischem Sand. Wege in die Gesellschaftsgeschichte Brandenburgs, 1700-1914. Hrsg. von Bernd Kölling und Ralf Pröve, Bielefeld 1999, S. 245 f.

54 Vgl. Friedrich II., Das militärische Testament von 1768 (wie Anm. 51), S. 236.

55 Kleinschmidt, Tyrocinium Militare (wie Anm. 31), S. 266 f. und Kloosterhuis, Donner, Blitz und Bräker (wie Anm. 19), S. 165-173.

56 August von Witzleben, Aus alten Parolebüchern der Berliner Garnison zur Zeit Friedrichs des Großen, Berlin 1851, S. 11. 
gen in der Gewaltanwendung gegenüber Soldaten haben bereits gezeigt, daß Soldaten und Offiziere zumindest eine Vorstellung von bestimmten Rechten der Soldaten hatten. Dreyer macht dies in einer Bemerkung über die Ausbildung unter dem Soldatenkönig deutlich: »Sein Feldherr, der alte Dessauer, fackelte auch nicht, wenn es nicht nach Ordre ging. [...] Gerechtigkeit wurde aber auch gehandhabt, ich hätte keinem Offizier rathen wollen, einen andern Weg zu betreten, er würde übel angekommen seyn ${ }^{57}$. Er ruft aber sicher nicht zur Insubordination auf. Schließlich zeigt er uns sehr deutlich seine eigene Motivation als Soldat in den drei Schlesischen Kriegen: »Wir schlugen den Feind aus Pflicht und Gehorsam gegen unsre Obrigkeit und den König ${ }^{58}$.« Deutlich wird, daß ein Soldat, der die gesamte Hierarchie verinnerlicht hat, von klaren Grenzen ausgeht und bei aller ideologischen Verurteilung mangelnden Gehorsams den Soldaten bei Überschreitung dieser Grenzen seitens der Vorgesetzten entsprechende Reaktionen zubilligt. Zu einem ähnlichen Schluß kommt Jörg Muth in seiner Untersuchung der Desertion in der Potsdamer Garnison ${ }^{59}$. Hinzu kommt, daß die Anwendung der Prügelstrafen offenbar von Einheit zu Einheit unterschiedlich gehandhabt wurde ${ }^{60}$. In der Ausbildung wurde vor allem Wert darauf gelegt, daß die Soldaten die technischen Abläufe beherrschten. Der Offizier hatte in erster Linie »Fachwissen « weiterzugeben. Wurde in der individuellen Ausbildung auf eine "sanfte" Vermittlung von Wissen und Erfahrungen Wert gelegt, so trat beim Exerzieren mit dem Bataillon der Zwang in den Vordergrund. Fluchen und Anschreien scheinen ebenso alltäglich gewesen zu sein wie Schläge mit dem Stock. Die Kommunikation war in erster Linie einseitig.

\section{Die Kommunikation im Kampf}

Mit dem Beginn des Gefechts änderten sich die Rahmenbedingungen für die Kommunikation zwischen Offizieren und Soldaten. Angst und Streß konnten die Aufmerksamkeit der Soldaten vermindern ${ }^{61}$ und Offiziere konnten außerstande sein, sinnvolle Befehle zu erteilen ${ }^{62}$. Besonders schockierend war offenbar die Verstümmelung von Kameraden und Freunden ${ }^{63}$. Der durch das Abfeuern der Musketen

57 Joseph Ferdinand Dreyer, Leben und Thaten eines preußischen Regiments-Tambours. Mit einer Einführung von Hans Bleckwenn, Neudr. der Ausg. Breslau 1810, Osnabrück 1975, S. 20.

58 Ebd., S. VIII, S. 1, S. 22.

59 Muth, Flucht aus dem militärischen Alltag (wie Anm. 19).

60 Ebd., S. 69 f. Kritik am »Prügelregiment« des Markgrafen Heinrich von BrandenburgSchwedt in: Legendäre »lange Kerls«. Quellen zur Regimentskultur der Königsgrenadiere Friedrich Wilhelms I. 17.13-1740. Hrsg. von Jürgen Kloosterhuis, Berlin 2003, S. 265-267.

61 Bräker, Das Leben und die Abentheuer (wie Anm. 3), S. 154. Vgl. »Extrakt Schreibens von Herrn Kistenmacher, Sekretär Sr. Durchlaucht des Herzogs von Bevern«, in: Briefe (wie Anm. 12), S. 8.

62 Charles Etienne Warnery, Feldzüge Friedrichs des Zweyten, Königs von Preußen, seit 1756 bis 1762, Hannover 1789, T. 1, S. 25 f.; Politische Correspondenz Friedrichs des Grossen (redigiert von Dr. Albert Naudé), Berlin 1887, Bd 15, S. 123.

63 Dreyer, Leben (wie Anm. 57), S. 28; Jany, Geschichte der preußischen Armee (wie Anm. 11), Bd 2, S. 245. »Tagebuch eines Hauptmanns (Maximilian von Bornstädt, gest. 1759) vom Langenauischen Grenadierbataillon, von dem Feldzug in Böhmen und in Schlesien, vom 
und Kanonen und das Schreien der Verwundeten hervorgerufene Lärm machte eine verbale Verständigung oft unmöglich. Pulverdampf und Staub führten schnell dazu, daß selbst die Fahnen des Bataillons nur noch schemenhaft zu erkennen waren. Hinzu kam, daß durch Tod, Verwundung, Streß und die Beschaffenheit des Geländes die Formationen durcheinander gerieten, so daß ein geregeltes Pelotonfeuer nicht mehr möglich war ${ }^{64}$.

Nach dem eigentlichen Kampfbeginn waren die Einflußmöglichkeiten des Oberkommandierenden weitgehend auf den Einsatz von Reserven oder ein sichtbares Beispiel persönlicher Tapferkeit beschränkt ${ }^{65}$. Barsewisch berichtet, daß die Anwesenheit des Königs bei seinem Regiment in der Schlacht bei Hochkirch dazu beitrug, die Soldaten in der Kampflinie zu halten ${ }^{66}$. Ähnliches berichtet der Musketier Dominicus aus der Schlacht bei Kunersdorf ${ }^{67}$. Oft genug ging jedoch in Verwirrung, Todesangst, Lärm und Rauch die Tätigkeit des Monarchen unter. Als Friedrich bei Zorndorf eine Fahne nahm, um ein zurückweichendes Füsilierregiment wieder gegen die russischen Linien zu führen, kümmerte dies die Soldaten herzlich wenig ${ }^{68}$. Ein ähnlicher Versuch scheiterte auch in der Schlacht bei Kunersdorf. In der Schlacht bei Kolin versuchte der König vergeblich, die preußische Reiterei zum Angriff zu bewegen. Bitten half genauso wenig wie Fluchen und der größte Teil seiner Kavallerie verschwand vom Kampffeld ${ }^{69}$.

Bis zum Beginn des eigentlichen Kampfes spielten die Linienoffiziere vor allem die Rolle eines »Transmissionsriemens « zwischen den Befehlen der Generäle und den einfachen Soldaten ${ }^{70}$. Der Fahnenjunker Barsewisch schildert das Vorgehen seines Bataillons zu Beginn der Schlacht bei Leuthen ${ }^{71}$. Friedrich II. hatte ihn angewiesen, direkt auf eine Stellung württembergischer Grenadiere zuzumarschieren.

»Hierbei ist noch zu bemerken, daß Se. Majestät uns während dem Avanciren [Vorrücken] einige Male einen Adjutanten schickten mit dem Befehl, wir soll-

Jahr 1745 vom April bis zum October«, in: Sammlung (wie Anm. 49), T. 1, S. 386; »Extrakt Schreibens eines Soldaten Hülsischen Regiments Namens Frantz ReiS, Lobositz, 6. Oktober 1756 «, in: Briefe (wie Anm: 12), S. 30; Aus dem siebenjährigen Krieg. Tagebuch des preußischen Musketiers Dominicus. Hrsg. von Dietrich Kerler, Neudr. der Ausg. München 1891, Osnabrück 1972, S. 10.

64 Vgl. Friedrich Wilhelm von Gaudi, Abschriften des Journals vom 7jährigen Kriege von von Gaudi, o. O. 1757, T. I, S. 76 f.

65 Duffy, The Military Experience (wie Anm. 8), S. $238 \mathrm{f}$.

66 . Ernst F.R. von Barsewisch, Von Rossbach bis Freiberg 1757-1763. Tagebuchblätter eines friderizianischen Fahnenjunkers und Offiziers, Neuausg. des Erstabdr. 1863, komm. und bearb. von Jürgen Olmes, Krefeld 1959, S. 75.

67 Aus dem siebenjährigen Krieg (wie Anm. 63), S. 64.

68 Jany, Geschichte der preußischen Armee (wie Anm. 11), S. 491.

69 Maximilian Ritter von Hoen, Die Schlacht bei Kolin am 18. Juni 1757, in: Streffleurs Militärische Zeitschrift, 1 (1911), H. 5, S. 789.

70 Vgl. Duffy, The Military Experience (wie Anm. 8), S. 221. Es scheint jedoch fraglich, ob die hier zitierte These Warnerys auf den Gesamtverlauf der Schlachten und Gefechte ausgedehnt werden kann. Warnery zeigt an anderen Stellen ein gerüttelt Maß an Verachtung für die bloßen »Linienoffiziere « und ès gibt eine Vielzahl von Berichten aus der Feder von Linienoffizieren der Infanterie, die darauf hindeuten, daß sie mit ihren Pelotons oder »Divisionen« (zwei Pelotons) durchaus eigenständig kämpfen musten und konnten.

71 Vgl. Bernhard R. Kroener, Die Geburt eines Mythos - die "schiefe Schlachtordnung ". Leuthen, 5. Dezember 1757, in: Schlachten der Weltgeschichte: von Salamis bis Sinai. Hrsg. von Stig Förster [u.a.], München 2001, S. 178 f. 
ten nicht so stark, sondern langsam avanciren. Unsere Soldaten hätten aber lieber den Feind im vollen Lauf sogleich angegriffen, so daß der Obrist Lieutenant von Bock und die übrigen Commandeurs derer Bataillons genug zu tun hatten, die Trouppen von dem allzu starken Avanciren zurückzuhalten, welches teils mit Güte und teils mit Gewalt geschehen mußte ${ }^{72}$.«

Zugleich hatten die vor der Einheit postierten Offiziere durch ihr eigenes Verhalten die Soldaten zu ermutigen ${ }^{73}$. Dies konnte dem weiteren Vorgehen dienen, aber auch durch zur Schau gestellte Kaltblütigkeit das Aushalten in einem brutalen Feuergefecht befördern. Derselbe Fähnrich berichtet aus der Schlacht bei Hochkirch, wie er und seine Offizierkollegen demonstrativ ruhig Schnupftabak zu sich nahmen $^{74}$.

Wie sich das im Reglement geforderte »leicht machen « konkret ausnahm, kann anhand einer Untersuchung der überlieferten Zurufe von Offizieren an Soldaten in kritischen Situationen nachvollzogen werden. Der Feldprediger Küster berichtet aus der Schlacht von Hochkirch:

"Ich stand neben dem Herrn Hauptmann von Vittinghofen. Er und ich redeten den Leuten zu: fest zu stehen, bis wir abgerufen würden ${ }^{75 !}$ « Die Luft ertönte von dem Rufen braver Officiere und Gemeinen, welche schrien: ১Kinder! Steht - Kammeraden! Haltet - es wird Sukkurs kommen! Ich vereinigte meine Stimme ungekannt mit ihnen und rief: >Kinder thut eure Pflicht, Gott wird uns helfen, der König wird bald mit mit Sukkurs kommen ${ }^{76}$."

Küster gibt Soldaten Geld, die Gewehre haben oder sie wieder aufnehmen, »während das Fluchen, Bitten und Befehle der Officiere wieder Ordnung in den gedrängten Körper zu bringen suchten « ${ }^{77}$. „Wir glaubten alle Augenblick, daß sie nun auf uns einhauen würden, und Viele sagten: Nun nü Gott befohlen und brav! Nun kommt die Reihe auch an uns. Aber es geschahe nicht ${ }^{78}$. « Über den Rückzug der Preußen vom Schlachtfeld bei Hochkirch berichtet Küster:

»Plötzlich sagte, als mit einem Munde, die ganze Linie: die feindliche Infanterie kommt gerade auf uns zu. Und die Kavallerie kam schon in voller Carriere im halben Zirkel auf unsern rechten Flügel auf uns zu, aber in solcher Entfernung, daß man es nur mit guten Augen sehen konnte. Nun sagten einige Gemeinen: 'nun ist uns das letzte Brod gebacken; die Infanterie kommt von vorne und die Kavallerie von der Seite. (Andere antworteten: slaß sie kommen, wir sind auch da!< Ich erwiederte: >Gott ist auch da! Gottes Schrecken kann sie zurücktreiben.` Indem kam der etwas vorwärts gerittene Major von Deging zurück und gebot Stille. Der Herr Obrist von Saldern, welcher die Bewegung des Feindes beobachtet hatte, näherte sich mit Kaltblütigkeit an die Linie, und sagte: wenn sie nur kommen, so wollen wir ihnen entgegen bürsten, daß sie das Wiederkommen vergessen ${ }^{79}$ !

Barsewisch, Von Rossbach (wie Anm. 66), S. 37.

"Schreiben des Feldwebels Liebler. Im Lager bei Prag, den 7. Mai 1757 «, in: Briefe (wie Anm. 12), S. 47; Winterfeldt, Relation von der Bataille bei Prag (wie Anm. 5), S. 436.

Barsewisch, Von Rossbach (wie Anm. 66), S. 77 f.

Carl Daniel Küster, Bruchstück seines Campagnelebens im siebenjährigen Kriege, 2. Aufl., Berlin 1791, S. 44.

Ebd., S. 37.

Ebd., S. 38.

Ebd., S. 41.

Ebd., S. $57 \mathrm{f}$. 
Von religiösen Bezügen berichtet jedoch nicht nur der Stabsfeldprediger. So schreibt Hülsen über sein eigenes Verhalten während der Schlacht bei Zorndorf, nachdem sein Regiment schon drei russische Treffen geschlagen, eine Batterie erobert und eine russische Fahne genommen hat. »Ich nahm jetzt die Fahne und rief: >Victoria, Bursche! Victoria! In Gottes Namen, immer weiter. Es wird bald ein Ende haben ${ }^{80 !} \ll$ Fast identisch ist ein Zuruf des Generalleutnants Prinz Friedrich Eugen von Württemberg während der Schlacht bei Kunersdorf, den uns Dominicus überliefert: "Marsch in Gottes Nahmen! sie sind schon am Reteriren ${ }^{81}$. " Die folgenden beiden Passagen sprechen das patriarchale Verhältnis zwischen Kommandeur und Soldaten an. Die preußische Infanterie des Rgt. Bevern hatte sich auf einer Anhöhe zusammengezogen und hielt das feindliche Feuer aus, obwohl sie keine Munition mehr hatte. "Kinder", rief ihnen der Herzog zu, "schießset doch um Gotteswillen, schießet, avanciret! « Ach, lieber Vater «, schrieen die Burschen wieder, »was sollen wir nun machen? Wir haben kein Pulver mehr, und müssen uns hier ohne Gegenwehr todtschießen lassen «. "Was«, rief der Herzog ihnen zu, "habt ihr denn keine Bajonetts, stecht die Hunde todt ${ }^{82} \ll$.

Auch Friedrich II. soll bei Kunersdorf den letzten Widerstand mit den Worten organisiert haben: »Kinder verlaßt mich nicht! [...] Wer ein braver Soldat ist, der folge mir $^{83 !}$ « Das Thema des "braven Soldaten « taucht auch kurz vor dem Tod des Marschalls Schwerin in der Schlacht bei Prag auf:

»Er eilte hinzu, ergrif eine Fahne und rief: Wer ein braver Mann ist, folge mir! Alle Officiers und der größte Theil der Soldaten thaten solches. Hier wurde er von einer Kartätschenkugel getödtt und sein Regiment so weit repoußirt, daß Winterfeld, zu dessen Division es gehörte, viel Mühe hatte, selbiges aufzuhalten, wenn er sich schon halb heisch [heiser] deshalb schriee ${ }^{84}$."

In bestimmten Fällen mußten die Offiziere gegen ängstigende Erfahrungen argumentieren. Prittwitz erinnert sich an eine Situation in der Schlacht bei Zorndorf, als die Soldaten feindliche Kavallerie sehen und an das Gemetzel bei Kolin erinnert werden. Doch die russische Reiterei wird vom zweiten Treffen des linken Flügels vertrieben.

»Es war ein Glück für uns, daß die Sache einen solch glücklichen Ausgang genommen, weil unsere Leute den Vorgang bei Kolin noch immer in frischem Gedächtnis behielten, daher, als sie sahen, was da vorging, wurden sie bereits in solchen panischen Schrecken versetzt, daß sie schon lange Hälse machten und zur Flucht sich anzuschicken schienen; dieses Benehmen verursachte unter den Offizieren eine große Sensation, so daß sie ihre ganze Beredsamkeit aufbieten mußten, um sie nur zu beruhigen ${ }^{85}$."

80 Unter Friedrich dem Großen. Aus den Memoiren des Aeltervaters 1752-1773. Hrsg. von Helene von Hülsen, Berlin 1890, S. 89.

81 Aus dem siebenjährigen Krieg (wie Anm. 63), S. 60.

82 Briefe (wie Anm. 12), S. 10. Retzow berichtet auch vom Befehl zum Angriff mit dem Bajonett, gibt aber die Anrede »Burschen«, statt Kinder wieder. Der Brief scheint jedoch aufgrund der zeitlichen Nähe glaubhafter. Vgl. Friedrich August Retzow, Charakteristik der wichtigsten Ereignisse des siebenjährigen Krieges, in Rücksicht auf Ursachen und Wirkungen, Berlin 1802, T. 1, S. 63.

83 Aus dem siebenjährigen Krieg (wie Anm. 63), S. 64.

84 Warnery, Feldzüge (wie Anm. 62), T. 1, S. 99 f.

85 Christian Wilhelm von Prittwitz, "Ich bin ein Preuße ...". Jugend und Kriegsleben eines preußischen Offiziers im Siebenjährigen Krieg, Paderborn 1989, S. 95. 
Die Situation einer Einheit im Kampf konnte auch auf andere Weise als Motivation genutzt werden. Friedrich II. sagte zu den Soldaten des Regiments Meyerinck, welches den ersten Angriff in der Schlacht bei Leuthen anführen sollte:

»Burschen, seht Ihr dorten wohl die Weißröcke? Die sollt ihr aus der Schanze wegjagen! Ihr müßt nur stark auf die anmarschieren und sie mit dem Bajonnet daraus vertreiben. Ich will Euch alsdann mit fünf Grenadier Bataillons und der ganzen Armée unterstützen. Hier heißt es: Siegen oder Sterben! Vor Euch habt Ihr den Feind und hinter Euch die ganze Armée, so daß Ihr also auf keiner Seite zurück oder vorwärts anders als siegend Platz findet ${ }^{86} . \ll$

Die Rivalität zwischen verschiedenen Waffengattungen konnte auch gegenüber der Infanterie motivierend genutzt werden. Ein Unteroffizier des Regiments Anhalt berichtet aus der Schlacht bei Lobositz: »Gleich darauf kam Graf Friedrich wieder, und sagte zu unserm Obristen: ,Was die Kavallerie verdorben hat, das werden die Herren Infanteristen verbessern, Ihr Bursche, Ihr werdet es wieder gut machen ${ }^{87}$. "Warnery berichtet einen besonderen Fall psychischen Einfühlungsvermögens aus der Belagerung von Schweidnitz durch die Preußen im Jahre 1762:

"Es ist wahr, daß die Regimenter, welche man zu dieser Belagerung brauchte, von den schlechtesten in der Armee waren, und fast ganz aus Kindern bestanden. Als die Garnison einst einen Ausfall that, fiengen verschiedene an zu weinen. Der Oberste von der Trenschee, welcher fürchtete, daß sie noch etwas Schlimmers thun möchten, mishandelte sie keineswegs, sogar nicht einmal mit Worten, sondern rief ihnen zu: Weint soviel ihr wollt, meine Kinder, aber feuert und lauft nicht davon. Diese Sanftmuth bewürkte, daß sie sich gut hielten ${ }^{88}$." In den Zurufen spielt die Religion eine zentrale Rolle. Der Soldat wird an seine Verpflichtung gegenüber Eid und Obrigkeit erinnert. Gottes Beistand kann sich nicht nur im Sinne des physischen Überlebensinteresses positiv auswirken. Auch die christliche Jenseits-Vorstellung wird angesprochen, da der Tod als »braver Soldat« das ewige Leben verheißen kann.

Als ebenso wichtig erscheint das physische Überleben. Offiziere versuchen immer wieder, den Soldaten ihre Situation so darzustellen, daß sich ihre Chancen, gesund aus dem Kampf zu kommen, durch das Weiterkämpfen oder Angreifen erhöhen werden. Ein dritter Aspekt betrifft den Stolz auf die eigene Armee, das Regiment und kann in Verbindung mit der allgemeinen Erfüllung der Pflichten des Soldatenstandes auftauchen ${ }^{89}$.

Briefe (wie Anm. 12), S. 3 f.

88 Warnery, Feldzüge (wïe Anm. 62), T. 2, S. 217. Cogniazzo hält die Stelle für erfunden, führt aber als Beweis nur an, daß die preußischen Soldaten der letzten Kriegsjahre gut gekämpft hätten. Da die "Kindersoldaten « jedoch stehen bleiben, ist dies kein Argument gegen Warnerys Darstellung. Vgl. Jacob de Cogniazzo, Geständnisse eines östreichischen Veterans in politisch-militarischer [!] Hinsicht auf die interessantesten Verhältnisse zwischen Oestreich und Preußen, während der Regierung des Großen Königs der Preußen Friedrichs des Zweyten mit historischen Anmerkungen gewidmet den königlich-preußischen Veteranen von dem Verfasser des freymüthigen Beytrags zur Geschichte des östreichischen Militär-Dienstes, Neudr. der Ausg. Breslau 1791, Bad Honnef 1982, T. 4, S. 188-195.

89 Vgl. auch: [Carl Daniel Küster,] »Einige psychologische Erfahrungen über Vergnügen und Misvergnügen der Krieger im Getümmel der Schlacht«, in: Officier-Lesebuch historisch-militairischen Inhalts, mit untermischten interessanten Anekdoten. Hrsg. von Carl Daniel Küster. Neudr. der Ausg. Berlin 1794, Starnberg 1988, T. 2, S. 88-90. 


\section{Einflüsse auf das Kampfverhalten von Soldaten}

Die taktische Situation: Eine zentrale Rolle spielte die sogenannte taktische Situation der Einheit. Es hat sich gezeigt, daß alle Ermutigung und Drohung nichts nutzten, wenn zu viele Soldaten vom Gegner getötet oder verstümmelt wurden. Panik konnte offenbar einsetzen, wenn in kurzer Zeit besonders viele Männer getötet oder verletzt wurden. Bei Prag »litten« einige preußische Infanterieregimenter "ganz außerordentlich". Das Regiment Winterfeld (Nr. 1) verlor fast 1100 seiner Angehörigen. Dabei hatte es mehrere auf Hügeln postierte österreichische Artilleriestellungen, z.T. wohl ohne zu schießen, erobert. Demgegenüber waren die Verluste der Grenadierbataillone, die beim ersten Angriff als "konfuser Klumpen "90 geflohen waren, niedriger. Mit durchschnittlich 240 Toten und Verstümmelten pro Bataillon $^{91}$ waren diese immer noch außerordentlich hoch. Es wird aber hinreichend deutlich, daß mit einiger Wahrscheinlichkeit die Kürze der Zeit, in der die Verluste eintraten, für die Flucht verantwortlich war ${ }^{92}$. Entscheidend war die Einschätzung der überlebenden Soldaten, in nächster Zukunft selbst zum Opfer zu werden.

Für die vorliegende Fragestellung ist der Umstand von besonderer Bedeutung, daß das Fehlschlagen eingeübter Verhaltensweisen zu längerfristigen Störungen in der Kommunikation zwischen Offizieren und Soldaten im Gefecht führen konnte. Die von Prittwitz angesprochenen üblen Erfahrungen seines Regiments in der Schlacht bei Kolin waren genau so beschaffen. Angesichts eines österreichischen Kavallerieangriffs auf den Rücken seiner Einheit ließ der Kommandeur das dritte Glied kehrtmachen und auf die Reiter schießen ${ }^{93}$, "so wie es im Reglement steht $\ll^{94}$. War eine solche Erfahrung die erste in einem Feldzug, konnte sie prägend werden ${ }^{95}$ und es bedurfte außerordentlicher Umstände, daß ein Regiment wieder $\mathrm{Zu}$ trauen in die eigenen Fähigkeiten erlangte ${ }^{96}$. Offenbar wurde die akkurate Ausführung der Befehle als Überlebensstrategie gesehen. Versagte sie, konnten auch Gewalt und Drohungen nicht weiterhelfen.

Ehre: Für den Offizier waren die Vermehrung der eigenen Ehre, bzw. die Angst vor dem Verlust derselben, zentral bei der Bekämpfung der eigenen Ängste. Ideal war das kaltblütige Aushalten im Kampf und dadurch die Fähigkeit, mit anderen Offizieren oder "Gemeinen " so zu kommunizieren, daß der militärische Erfolg sichergestellt wurde ${ }^{97}$. Ein Offizier konnte Ehebrechen ${ }^{98}$ oder seine freie Zeit in Ber-

90 Winterfeldt, Relation von der Bataille bei Prag (wie Anm. 5), S. 436.

91 Maximilian Ritter von Hoen, Die Schlacht bei Prag, in: Streffleurs Militärische Zeitschrift, 1 (1911), H. 3, S. 412.

92. Duffy, The Military Experience (wie Anm. 8), S. 249 f.

93 Prittwitz, »Ich bin ein Preuße ..." (wie Anm. 85), S. 57-59.

94 Vgl. Tempelhof, Geschichte (wie Anm. 46), Bd 1, S. $218 \mathrm{f}$.

95 Dies scheint bezüglich mehrerer ostpreußischer Regimenter der Fall gewesen zu sein. Sie wurden wider Erwarten in ihrem ersten Einsatz in der Schlacht bei Groß-Jägersdorf geschlagen und flohen dann zusammen mit Prittwitz' Regiment (von Bevern) im folgenden Jahr in der Schlacht bei Zorndorf.

96 Vgl. die im folgenden Abschnitt geschilderte Geschichte des Regiments Anhalt.

97 Vgl. [Carl Daniel Küster,] »Ein Traum stimmte einen Officier im siebenjährigen Kriege zur kaltblütigen Tapferkeit", in: Officier-Lesebuch (wie Anm. 89), T. 2, S. 103-105. Anekdoten, in: Neues Militärisches Journal, Bd 2, S. 273. 
lin im »Blutigen Finger «, einem stadtbekannten Bordell, zubringen ohne ernste Probleme zu bekommen". Lief er hingegen im Gefecht davon, waren die Folgen fatal: "Gott, o Gott! - So wie er zu fallen, das ist schrecklich! - Das Bild dieses Schurken steht tief vor meiner Seele! - Alles floh ihn wie einen Aussätzigen ${ }^{100 . \ll}$

Zeitgenössische Autoren berichten, daßß in der preußischen Armee der Ehrbegriff unter vielen Soldaten fest verankert war ${ }^{101}$. Er wird als auf zwei Ebenen wirksam geschildert:

- Die besondere Zuwendung seitens der Krone gegenüber dem Militärstand und der militärische Erfolg der Armee erzeugten Stolz auf die eigenen Leistungen ${ }^{102}$.

- Die Ehre des Regiments als sozialer Gruppe, die das Leben der Soldaten bestimmte, konnte vermehrt, aber auch verteidigt werden.

Das wohl bekannteste Beispiel für die Wirksamkeit dieser Vorstellung im Kampf ist das Verhalten des Regiments Anhalt in der Schlacht bei Liegnitz. Friedrich II. hatte das Regiment beschuldigt, bei der kurz zuvor aufgehobenen Belagerung von Dresden zu früh geflohen zu sein, und ließ ihm Säbel und Tressen abnehmen. Dies kam einer kollektiven Ausstoßung gleich. $\mathrm{Zu}$ dem Regiment versetzte Offiziere anderer Einheiten weigerten sich, unter entehrten Leuten zu kämpfen. Bei Liegnitz rückte das Regiment aus eigenem Antrieb in das erste Treffen, stürmte mit dem Ruf "Ehre oder Tod! « auf die Österreicher los und schlug sogar gegnerische Reiterei durch einen Bajonettangriff in die Flucht ${ }^{103}$. Auch Ulrich Bräker berichtet, daß ihm während seiner Flucht vom Schlachtfeld bei Lobositz mehrere Soldaten begegneten, die ihn mit einem »Victoria « zum Mitkommen und Weiterkämpfen aufforderten ${ }^{104}$. Das Ehrgefühl unter den Soldaten konnte sich also auch auf die Bindungsfähigkeit und Effizienz der sozialen Nahgruppe auswirken.

Materielle Anreize: Ende April 1758 erwähnte Friedrich II. gegenüber seinem Vorleser de Catt:

"Ich ermutige meine Soldaten [...], ich belohne sie, und wenn es nötig ist, verspreche ich ihnen diese Belohnungen schon vorher, um sie anzuspornen. Nach der Schlacht bei Breslau [Dort wurde ein preußisches Heer unter dem Kommando des Herzogs von Bevern am 22. November 1757 von österreichischen Truppen geschlagen.] fürchteten sie sich vor den Kanonen; da versprach ich hundert Dukaten für.jede Kanone, die ein preußischer Soldat eroberte, und das hatte einen wunderbaren Erfolg ${ }^{105}$.

99 Duffy, Friedrich der Große und seine Armee (wie Anm. 14), S. 63

100 Unter Friedrich dem Großen (wie Anm. 80), S. 46.

101 Vgl. Lossow, Denkwürdigkeiten (wie Anm. 53), S. 57. »Fortsetzung der Recension über die Beyträge zur Kriegskunst und Geschichte des Kriegs von 1756 bis 1763 mit Plans und Karten, 4 tes Stück, von Tielcke, Churfürstl. Sächs. Artilleriehauptmann, Freyberg, gedruckt mit Barthelschen Schriften, 4, 1782«, in: Bellona 1783, Stk. 10, S. 98.

102 Ausführlicher Auszug und Bemerkungen über den militärischen Theils des Werks. De la Monarchie prussienne sous Frédéric le grand p. M. le Comte de Mirabeau 1788, in: Neues Militärisches Journal, Bd 2, S. 59. Der »Ehrenpunkt « wird hier als entscheidend für die besondere Tapferkeit der preußischen Armee angesehen.

103 Retzow, Charakteristik (wie Anm. 82), T. 2, S. 244.

104 Bräker, Das Leben und die Abentheuer (wie Anm. 3), S. 156. Vgl. auch Sergeant Johann Ludwig Rehens. Ein württembergischer Veteran im Regiment v. Waldeck, in: Bauern, Bürger und Soldaten. Quellen zur Sozialisation des Militärsystems im preußischen Westfalen 1713-1803. Bearb. von Jürgen Kloosterhuis, Münster 1992 (= Veröffentlichungen der staatlichen Archive des Landes NRW, Reihe C, Bd 29), S. 336 f.

105 Friedrich der Große. Gespräche mit Catt. Hrsg. von Wilhelm Schüßler, Leipzig 1940, S. 43. Vgl. Tempelhof, Geschichte (wie Anm. 46), T. 1, S. 241. 
Die Anordnung, für Beutestücke Geld an die Soldaten auszugeben, findet sich schon im Reglement von 1726 und wird 1743 wörtlich wiederholt:

»Wenn ein gemeiner Soldat von dem Feinde eine Fahne, Standarte oder Paucke erobert, soll er allezeit ein gut Stück Geld davor bekommen, wenn es aber ein Officier oder Unter-Officier ist, wird sich selbiger dadurch recommandiren, und ohnfehlbahres Avancement zu gewarten haben ${ }^{106}$."

Entsprechende Zahlungen sind z.B. für die Schlacht bei Kesselsdorf (1745) belegt ${ }^{107}$. Sogenannte »Douceurgelder «, also Geldgeschenke für die Unteroffiziere und »Gemeinen " besonders tapferer oder erfolgreicher Formationen, wurden schon vor Oktober 1757 »gereicht $\ll^{108}$.

Kanonengelder im eigentlichen Sinne zahlte Friedrich zum ersten Mal nach der Schlacht bei Breslau an dás Grenadierbataillon Kahlden, das als einziges Bataillon "aus dieser Schlacht Kanonengelder erhielt «109. Vor der Schlacht bei Leuthen kündigte Friedrich dann in der Ansprache an, »für die Eroberung eines jeden Canons [...] 100 Dukaten [zu] bezahlen «110. Die Summe wird durch ein Schreiben des Majors von Heyden an Fürst Moritz bestätigt, der am 3. Januar.1758 die versprochenen 100 Dukaten "vor jedes eroberte Kanon " anmahnt ${ }^{111}$. Warum allerdings das Grenadierbataillon von Oestenreich ${ }^{112}$ nur $" 50$ Ducaten zum Douceur « bekam ${ }^{113}$, bleibt ein Rätsel. Später wurden entsprechende Gelder regelmäßig ausgesetzt und kamen offenbar auch pünktlich an ihre Adressaten. So ließ der König schon zwei Tage nach der Schlacht bei Liegnitz (15. August 1760) die den Offizieren versprochenen Belohnungsgelder "und an die Regimenter, vor die erbeuteten Kanonen, vor jegliche 137 Rthlr. 12 gl., und vor die Estandarten und Fahnen, vor jegliche 50 Rthlr. bezahlen « ${ }^{114}$. Das Versprechen von Geldgeschenken macht deutlich, daß der Kö-

106 Reglement von 1726 (wie Anm. 6), S. 363. Reglement von 1743 (wie Anm. 6), T. 1, S. 349.

107 „Geschichte und Feldzüge des Dragonerregiments von Borke, vom Jahr 1717 da es gestiftet worden, bis zum Julius 1784", in: Sammlung (wie Anm. 49), T. 5, S. 311.

108 »Bericht des Obristen von Carlowitz von den Feldzügen seines Grenadierbataillons von 1744 bis 1763 «, in: Sammlung (wie Anm. 49), T. 4, S. 227. Offenbar wurden entsprechend benannte Gelder auch regelmäßig und in einer festgesetzten Höhe während der Winterquartiere ausgezahlt, sog. "Winterdouceurs«. Ein preußischer Offizier berichtet, daß Ende März 1760 an die Offiziere seines Regiments pro Hauptmann 200 statt der zustehenden 500 Rthlr. und an jeden Subalternoffizier die festgelegten 50 Rthlr. ausbezahlt wurden. "Tagebuch eines Preußischen Offiziers über die Feldzüge von 1756 bis 1763 «, in: Sammlung (wie Anm. 49), T. 2, S. 391. Diese sind nicht mit den an alle Offiziere nicht in Ungnade gefallener Einheiten regelmäßig gereichten »Winterdouceurs « zu verwechseln.

109 "Bericht des Obristen von Carlowitz von den Feldzügen seines Grenadierbataillons von 1744 bis 1763«, in: Sammlung (wie Anm. 49), T. 4, S. 228 f. Georg Karl von Carlowitz wurde 1759 Kommandeur dieses Bataillons, welches 1756-1757 von Henning Alexander von Kahlden befehligt wurde. Vgl. Gieraths, Die Kampfhandlungen (wie Anm. 29), S. 566 und 574 .

110 Barsewisch, Von Rossbach (wie Anm. 66), S. 29

111 Jany, Geschichte der preußischen Armee (wie Anm. 11), S. 451, Anm. 136.

112 Zum Namen vgl. Gieraths, Die Kampfhandlungen (wie Anm. 29), S. 580.

113 "Journal des Oesterreichischen Grenadier-Bataillons, in den Feldzügen von 1756 bis $1763 \lll$, in: Sammlung (wie Anm. 49), T. 5, S. 86.

114 »Tagebuch eines Preußischen Offiziers über die Feldzüge von 1756 bis 1763 «, in: Sammlung (wie Anm. 49), T. 2, S. 425. 
nig auf das Versagen anderer Mittel angesichts einer besonderen Bedrohung nicht mit gesteigertem Druck reagierte ${ }^{115}$, sondern auf eine positive Motivation setzte.

Nationale Stereotype: Bei den Offizieren und im Oberkommando, aber auch bei einfachen Soldaten sind negative nationale Stereotype vor allem gegenüber den Russen nachweisbar. Für die "Gemeinen « haben wahrscheinlich vor allem konfessionelle und sprachliche Barrieren eine Rolle gespielt. Zu diesen gesellten sich Animositäten gegenüber bestimmten Gegnern, die aus dem Kriegsverlauf entstanden, besonders den Österreichern. Sie dienten meist als Legitimation für Verhaltensweisen im Kampf, die eigentlich als regelwidrig galten, wie dem Niedermetzeln von fliehenden oder sich ergebenden Gegnern. Wirkungsvoll wurden sie aber erst im Zusammenhang mit Situationen, die auch gegenüber nicht-stigmatisierten Feinden regelwidriges Verhalten begünstigten und wenn die entsprechenden ethnischen Vorurteile von einer größeren Anzahl von Soldaten, Offizieren und der Heeresleitung geteilt wurden ${ }^{116}$.

Ständisches Ethos: Der Musketier Johann Christian Riemann schreibt angesichts des Todes seines Bruders in einem Gefecht um Pfingsten 1762:

"laßet uns mit unsers bruders Ehre trösten, er hat den ruhm in dieser welt gelaßen, das er als ein getreuer Krieges Knecht mit tapfern muth sein Blut vergoßen und Leben laßen vor sein recht, vor seines Königs Ehre, vor sein Vaterland und seine Bundesgenoßen und uns allen zu gute. Der liebe Gott gebe ihn die Ewige seligkeit davor, er ist aller noth entgangen und ist an den ort wo aller Krieg und Kriegesgeschrey ein Ende hat, ihn thut kein Canonen Knal mehr erschrecken ${ }^{117}$.«

In einem folgenden Schreiben schildert er seine Betrübnis über den Tod des Bruders,

»aber nach seiner gefährlichen Plessuer [Blessur, Verwundung] ist es sein Beste das er erlöset, er wäre doch sein Lebetage ein elender Kröppel gewäßen. er hat durch eine retliche That seinen Lauf vollführet und ich habe noch Täglich erkentnis meiner Sünden und erinnerung meines Todes durch drohurig unser wüttenden Feinde. [...] [Gott hat uns beigestanden] da unser Feinde alle rieffen: sie sind unser, der wird ferner den Preuschen Heer beistehen und nicht von seinen Worte abtreiben laßen. Gott und Friedrich lebet noch ${ }^{118}$."

Der letztgenannte Passus war der "standesübergreifende« Schutzspruch der preußischen Armee. Auch der Fahnenjunker Ernst Friedrich von Barsewisch schrieb angesichts seiner.

115 Nach der Massenflucht ostpreußischer Regimenter bei Zorndorf (1758) empfahl Friedrich seinem Bruder Heinrich, seiner »Infanterie strenge Disziplin aufzuerlegen und sie den Stock fürchten zu lehren«. Christopher Duffy, Friedrich der Große. Ein Soldatenleben, Augsburg 1994, S. 247.

116 Vgl. hierzu: Sascha Möbius, »Haß gegen alles, was nur den Namen eines Franzosen führet«? Die Schlacht bei Rossbach und nationale Stereotype in der deutschsprachigen Militärliteratur der zweiten Hälfte des 18. Jahrhunderts, in: Gallophobie im 18. Jahrhundert. Hrsg. von Albert Meier und Jens Häseler (im Druck).

117 »Brief des Musketiers Johann Christian Riemann. 16. Juni 1762«, in: Preußische Soldatenbriefe aus dem Gebiet der Provinz Sachsen im 18. Jahrhundert. Hrsg. von Georg Liebe, Magdeburg 1912, S. 32.

118 »Brief des Musketiers Johann Christian Riemann. Sommer 1762«, in: Preußische Soldatenbriefe (wie Anm. 117), S. 34 f. 
"Hoffnung bei der nächsten Schlacht mein Grab, als mein Avancement [Beförderung] zu finden [:] Aber bei der Preußischen Armée hieß es zu der Zeit: >Gott und der König.< - Dies sind unsere Hoffnungen, wobei wir uns vor der ganzen Welt Feinde nicht fürchten. Das erhielt uns allen den Mut und hat uns auch, und besonders mich, durch den ganzen noch folgenden blutigen Krieg und bis zu meiner jetzigen Stunde erhalten ${ }^{119}$.

Von Interesse ist in diesem Zusammenhang auch jener Brief, den der Kürassierkorporal Binn am 20. Juli 1759 in Erwartung einer großen Schlacht gegen die russische Armee ${ }^{120}$ schreibt. Daß die Zeit vor einer Schlacht angstbesetzt war, geht auch aus anderen Schilderungen hervor ${ }^{121}$. Explizit vermerkt Binn nichts über seine Beunruhigung, doch gibt der Brief einen sehr guten Einblick in seinen Umgang mit der Situation.

An vier Stellen findet sich die Figur "Gott [...] mach es nach seinem gnädigen Willen machen wie es ihm gefält «122 im Zusammenhang mit der Frage des eigenen Überlebens. Dies deutet auf große Anspannung und Ängste hin. Binn fordert seine Verwandten zur Fürbitte auf: »fallet auf eure Knie und bittet den lieben Gott das er uns und euch gnädig und den Sieg gegen unßere Tirranischen Feinde gibt.«

Binn führt noch andere Motive an, die ihm beim Umgang mit seinen Sorgen hilfreich sind:

- Die bevorstehende Schlacht kann die entscheidende gegen die als "Tirranen " bezeichneten Russen sein: »ich habe aber die Gedancken wan der liebe Gott uns gnädig ist und gibt uns den Sieg welcher Eintzig und allein von gott komt, so werden sie der maaßen so gepritscht werden das es als dann viel leicht woll das letzte mahl sein wird das sie fer so von kommen."

- Angesichts dieses Gegners würde es "schlecht aussehen wann die pottallie [Bataille, Schlacht] verspielt würde .

- Binn will »den Tirrannen nichts schenken sondern das jenige thun was einem rechtschaffnen Soldaten in Pottallien zu kommt « und bittet für sich und seine Kameraden, »daß der liebe Gott uns einen sehr Hertzhaften muth gibt unsern Feind anzugreifen «.

- Er denkt auch über die Alternativen nach und kommt zu dem Schluß, »lieber Todt als gefangen oder schwer pleßiert « ${ }^{123}$. Die besondere Angst vor einer schweren Verletzung, die den solchermaßen Verstümmelten zum »Kröppel« macht, findet sich auch in anderen Briefen. Auch ging das Gerücht um, daß die Russen alle Gefangenen brutal ermorden würden ${ }^{124}$.

119 Barsewisch, Von Rossbach (wie Anm. 66), S. 27. Auch: Küster, Bruchstück (wie Anm. 75), S. $73 \mathrm{f}$.

120 Am 12. August kam es dann bei Kunersdorf in der Nähe von Frankfurt an der Oder zur Schlacht.

121 Neben den bereits diskutierten Briefen ist hier z.B. Bräkers Lebensbeschreibung zu nennen. Bräker, Das Leben und die Abentheuer (wie Anm. 3), S. 151 f. Auch: Dreyer, Leben (wie Anm. 57), S. 15 F. Barsewisch, Von Rossbach (wie Anm. 66), S. 31.

122 "Brief Nr. 10 des Corporals Binn. 20. Juli 1759«, in: Preußische Soldatenbriefe (wie Anm. 117), S. 23.

123 Ebd., S. 22.

124 Warnery, Feldzüge (wie Anm. 62), T. 2, S. 22 f. 
Wenn Riemann seinen toten Bruder als "getreuen Krieges Knecht" schildert und Binn sich vornimmt, das zu tun, "was rechtschaffnen Soldaten in Pottallien zu kommt «, wird hier die Zugehörigkeit zum Soldatenstand als Motivation deutlich. $\mathrm{Da} ß$ dies als gottgefällig und im Jenseits belohnbar gesehen wird, zeigt vor allem der Text von Riemann sehr deutlich.

Religion: Der Glaube konnte auch Angst bekämpfen, wenn der Soldat davon überzeugt war, unter Gottes Schutz zu stehen ${ }^{125}$, oder wenn er davon ausging, daß er für die Erfüllung seiner Pflicht im Jenseits belohnt würde. Der folgende Passus von Küster zeigt, daß dies bei vielen Soldaten im Kampf wirken konnte, es aber ebenso andere Haltungen in dieser Frage gab:

»Da gleichwohl einige Feige zurückgegangen waren und sich in die Kochlöcher gelegt hatten, worüber brave Gemeine murreten und die Officiers sie mit Gewalt wieder in die Glieder trieben; so ging ich einige Schritte hinter die Fronte und sagte mit lauter Stimme: >Kinder, ich kenne euch nicht, aber Gott kennt euch! Wer im Kochloche todtgeschossen wird, stirbt als Deserteur, als ein schlechter Mensch, und sündigt noch in dem letzten Augenblicke seines Lebens; wer aber an seinem Berufsplatze stirbt, der thut doch zuletzt noch etwas Gutes. Verlaßt doch eure brave Kameraden nicht, es ist hier vorne sicherer, als da hinten. $<$ Es kamen auch manche zurück; ein Kurzgewehr aber ward von einem dieser Feigen nach mir geworfen, ohne daß es, Gott Lob! Mich traf ${ }^{126}$."

So scheint die Religion gerade im Kampf eine zentrale Rolle im Denken vieler Soldaten gespielt zu haben. Sie ist Trost angesichts der Gewalterfahrungen und gleichzeitig Motivation, die dem eigenen Stand zukommenden Pflichten zu erfüllen ${ }^{127}$. Diese Pflichten reichen vom »bei der Fahne bleiben« bis zum »dem Gegner nichts schenken«. Religion kann als Klammer interpretiert werden, die anderen Faktoren eine sa$k$ rale Bedeutung gab ${ }^{128}$. Der oftmals religiöse Gehalt vieler der zitierten Zurufe von Offizieren an Soldaten spricht also ein zentrales Denkmuster vieler »Gemeiner« an. Der Soldat wird an seine Verpflichtung gegenüber Eid und Obrigkeit erinnert. Gottes Beistand kann sich nicht nur im Sinne des physischen Überlebensinteresses positiv auswirken. Auch die christliche Jenseits-Vorstellung spielt eine Rolle, da der Tod als »braver Soldat « das ewige Leben verheißen kann. Das physische Überlebensinteresse erweist sich als nicht weniger wichtig. Offiziere versuchen immer wieder, den Soldaten ihre Situation so darzustellen, daß sich ihre Chancen, gesund aus dem Kampf zu kommen, durch das Weiterkämpfen oder Angreifen erhöhen werden. Ein anderer Komplex betrifft den Stolz auf die eigene Armee, das Regiment und kann in Verbindung mit der allgemeinen Erfüllung der Pflichten des Soldatenstandes auftauchen. Deutlich wird die Übereinstimmung zwischen den Zurufen der Offiziere und den ermittelbaren Interessen der Soldaten, besonders dem physischen und geistlichen Überlebensinteresse.

125 „Schreiben des Feldwebels Liebler. Im Lager bei Prag, den 7. Mai 1757«, in: Briefe (wie Anm. 12), S. 45. Ähnlich in Küster, Bruchstück (wie Anm. 75), S. 61.

126 Küster, Bruchstück (wie Anm. 75), S. 42.

127 Vgl. Sikora, Disziplin (wie Anm. 8), S. 282. Vgl. auch Grenadier Johann Hermann Dresel, an seinen Vater, Neuen bei Kloster Grüssau, 15. 5. 1759, in: Bauern, Bürger und Soldaten, (wie Anm. 104), S. 334 f.

${ }_{128}$ Vgl. Richard L. Gawthrop, Pietism and the Making of eighteenth-century Prussia, Cambridge 1993, S. 223-246. 


\section{Disziplin durch Gewalt?}

In der preußischen Armee des Siebenjährigen Krieges finden sich grundsätzlich vier Arten von direktem Zwang, der auf Soldaten ausgeübt werden konnte:

Aufstellung von Reiterei hinter Infanterieeinheiten: Der Feldmarschall Lehwald befahl in einer Disposition vor dem 29. Juli 1757: "Nach dem Aufmarsch soll jedes Husarenregiment eine Eskadron hinter das zweite Treffen schicken [...] desgleichen; wenn wo Leute nicht brav thun, noch heran gehen wollten, treiben sie solche vor ${ }^{129}$ " " Wahrscheinlich ergriff von Lehwald diese Maßnahme, weil im zweiten Treffen acht Garnisonbataillone standen ${ }^{130}$, die als »unzuverlässig « eingestuft wurden ${ }^{131}$.

Intakte Einheiten bekommen den Befehl, auf Fliehende zu schießen ${ }^{132}$. Dies wird von den Offizieren mit der Tapferkeit der intakten Einheiten begründet, woraus deutlich wird, daß das Feuer auf die Fliehenden durch deren »Feigheit« legitimiert wird.

Zugleich dient es dem Selbstschutz, da die von Panik ergriffenen Männer auch die formierten Bataillone durcheinanderbringen und damit gefährden können.

Zusammentreiben von Versprengten durch Reiter: Prittwitz berichtet dies aus der Schlacht bei Zorndorf ${ }^{133}$ und wird nach seiner Verwundung bei Kunersdorf selbst von schwarzen Husaren bedroht:

»Wir kamen bei einem Trupp schwarzer Husaren vorbei, der kommandierende Offizier hielt mich für einen unverwundeten Ausreißer und schickte zwei seiner Leute an mich ab unter der Drohung, mich niederzuhauen, wenn ich nicht sogleich umkehrte und ins Treffen zurückginge. Nachdem ich sie aber eines andern belehrt hatte, ließen sie mich weiterreiten ${ }^{134}$.«

Die Kontrolle durch hinter der Formation marschierende Offiziere, Unteroffiziere und Soldaten: Schläge scheinen hier keine Seltenheit gewesen zu sein ${ }^{135}$. Friedrich II. zog aus der Massenflucht des preußischen linken Flügels in der Schlacht bei Zorndorf den Schluß, daß die beteiligten ostpreußischen Regimenter schon in der Ausbildung den Stock fürchten lernen müssen. Darüber hinaus ordnete er die Verstärkung der hinter den Linien postierten Offiziere und Unteroffiziere durch »zuverlässige « Soldaten an $^{136}$. Die Drohung mit dem Töten von Fliehenden findet sich nicht nur im preußischen Reglement, sondern ist schon Bestandteil eidgenössischer Kriegsordnungen aus dem späten Mittelalter ${ }^{137}$. Prittwitz berichtet über einen Überfall von Kosaken auf seine Einheit, die in Verwirrung gerät.

"Nun muß ich beifügen, als meine Leute bei dieser Überraschung sahen, daß hinter ihnen alles lief, so waren auch sie bereits auf dem Sprunge. In der Angst aber ergriff ich meine Pistole und setzte sie einem Burschen auf die Brust, un-

»Disposition zum Marsch gegen den Feind und zur Bataille, als solcher noch am rechten Ufer des Pregels stand «, in: Bellona 1782, St. 5, S. 53.

130 Der Siebenjährige Krieg (wie Anm. 13), Bd 4, S. 88.

131 Bleckwenn gibt an, daß sie z.T. mit sächsischen Rekruten aufgefüllt wurden. Vgl. Hans Bleckwenn, Altpreußische Uniformen 1753-1786, Dortmund 1981; S. 53.

132 Briefe (wie Anm. 12), S. 3 f.; Aus dem siebenjährigen Krieg (wie Anm. 63), S. 60.

133 Prittwitz, "Ich bin ein Preuße ..." (wie Anm. 85), S. 96.f.

134 Ebd., S. 123.

135 Retzow, Charakteristik (wie Anm. 82), T. 1, S. 251.

136 Duffy, Friedrich der Große. Ein Soldatenleben (wie Anm. 115), S. 247.

137 Volker Schmidtchen, Kriegswesen im späten Mittelalter. Technik, Taktik, Theorie, Weinheim 1990, S. 232. 
ter der Drohung, ihn zu erschießen, wenn er nicht stände. Dieses wirkte und ich erreichte meine Zweck, obgleich die Pistole nicht geladen war ${ }^{138}$.«

$\mathrm{Daß}$ die Pistole nicht geladen war, verweist auf die Frage, wie ernst diese Drohungen gemeint waren. Der Bestimmtheit, mit der verlangt wurde, Fliehende niederzuschießen, steht der Befund entgegen, daß sich in den vorliegenden Quellen keine einzige Passage findet, die die Tötung eines preußischen Soldaten in einem entsprechenden Zusammenhang auch nur erwähnt. Die Tötung fliehender Österreicher schildert ein preußischer Soldatenbrief. Dort erzählt ein gefangener österreichischer Leutnant, »daß sein Kapitän [...] 10 Mann mit eigener Hand erstochen, welche hätten zurückweichen wollen, und viele mehr hätten dergleichen getan ${ }^{139}$ «. Die Passage stammt von dem Feldwebel Liebler, der berichtet:

»Die armen feindlichen Blessirten, so noch in Lobositz liegen, können uns nicht genug von ihrer Wuth und Zorn erzählen. Ihre Parole ist gewesen kein Pardon, und vorher haben sämmtlich müssen schwören, keinen Schritt zu weichen. Es hat sogar ein blessirter Lieutenant erzählet, daß sein Kapitän, so auf der Wahlstatt todt neben ihm gelegen, 10 Mann mit eigener Hand erstochen, welche hätten zurückweichen wollen, und Viele mehr hätten dergleichen gethan, auch haben sie unter währender Aktion ihre eigenen gefährlich Blessirten und Todten, so an der Elbe gelegen, ins Wasser geworfen, und sollen deren wohl etliche 100 hineingeworfen worden $\operatorname{sein}^{140}$.

Das Ertränken der eigenen Schwerverwundeten war sicher keine Praxis in der österreichischen Armee, so daß Zweifel an der Glaubwürdigkeit des Informanten aufkommen. Auf den verwundeten österreichischen Leutnant mag das zutreffen, was Bräker über preußische Deserteure und Gefangene nach derselben Schlacht berichtet: »Etliche indessen wußten Winds genug zu machen, und, ihren dießmäligen Wirthen [den österreichischen Bewachern] zu schmeicheln, zur Verkleinerung der Preussen hundert Lügen auszuhecken ${ }^{141}$.« Eine definitive Aussage über den Wahrheitsgehalt scheint unmöglich. Informativ ist der Text im Rahmen der vorliegenden Fragestellung dennoch. Denn in jedem Fall wird deutlich, daß die beschriebene Handlung nicht auf die Zustimmung der am Gespräch beteiligten Soldaten stößt. Der Kontext, in den das Niedermachen der eigenen Leute gestellt wird, ergibt sich aus dem Vorwurf der Regelverletzung. "Kein Pardon" geben und Verwundete ermorden widersprach diametral der Auffassung einer »zivilisierten « Kriegführung im 18. Jahrhundert. Cogniazzo vergleicht es mit dem »Scalpiren der Haarschedel nach Art der Illinoisen « ${ }^{142}$.

So wird zumindest deutlich, daß es Offiziere und Soldaten gab, die die Ausführung des Befehls zum Töten von Fliehenden für regelwidrig und offensichtlich anstößig hielten. Auch ist Prittwitz' Bemerkung über die ungeladene Pistole bemerkenswert. Wenn es sich um einen generell sanktionierten Vorgang gehandelt hätte, wäre sie überflüssig. Eine gewisse Scheu vor der aktiven Drohung wird hier deutlich. Wir wissen aus anderen Bereichen, daß eine solche Doppelbödigkeit nichts

138 Prittwitz, »Ich bin ein Preuße ...« (wie Anm. 85), S. 115.

139 Sikora, Disziplín (wie Anm. 8), S. 166.

140 "Schreiben des Feldwebels Liebler. Im Lager bei Lobositz, den 12. Oktober 1756«, in: Briefe (wie Anm. 12), S. 34.

141 Bräker, Das Leben und die Abentheuer (wie Anm. 3), S. 158.

142 Cogniazzo, Geständnisse (wie Anm. 88), T. 3, S. 162. 
Ungewöhnliches in der Armee Friedrichs II. war ${ }^{143}$. Bei aller gebotenen Vorsicht angesichts der lückenhaften Quellenlage scheint sich der Befund abzuzeichnen, daß die Anordnung, weichende Soldaten niederzustechen, zumindest weitaus seltener ausgeführt wurde, als es die Bestimmtheit der Anordnungen suggeriert.

Körperliche Gewalt unterhalb des Tötens oder Verstümmelns wurde durchaus angewendet, und hier verlor aufgrund seines unehrenhaften Verhaltens auch der Offizier den Schutz vor körperlicher Züchtigung, den ihm sonst die Ehre gewähr$\mathrm{te}^{144}$. Einen eigenen Soldaten zu töten war hingegen etwas anderes und fiel sicher nicht leicht, besonders wenn sich beide Menschen kannten. Selbst ein als brutal und verächtlich wahrgenommener Obrist wie Manstein vom Regiment Anhalt $(\mathrm{Nr} .3)^{145}$ droht mit dem Niederschießen, läßt es aber nicht ausführen. Der deutlich freundlichere Hülsen verhält sich sogar reglementwidrig, weil er den Weggang eines Soldaten mitten in der Schlacht bei Zorndorf lediglich mit einer Beleidigung quittiert, der Soldat sich allerdings auch später wieder einstellt ${ }^{146}$. Eine andere Stelle bei Hülsen scheint einen weiteren wichtigen Hinweis zu enthalten. Er schildert den Zusammenbruch seines Regiments in der Schlacht bei Zorndorf folgendermaßen:

"Da aber der gemeine Mann drei Treffen geschlagen, das vierte vor sich, und dem Feind im Rücken sah, gab er auf das Rufen der noch lebenden Offiziere nicht Acht, sondern retirirte nach unserm rechten Flügel, der erst jetzt seine Operationen anfing. Es ist nicht möglich, daß Infanterie mit mehr Kopf und Herz fechten kann, als die Unsern es bisher gethan ${ }^{147}$. «

Offenbar gab es ein inoffizielles Maß, das ein Soldat auszuhalten hatte, wobei die Zahl drei eventuell eine Rolle spielte. Küster berichtet über die Schlacht bei Hochkirch:

"Als der Hochkircher Kirchhof zum zweytenmale gestürmt ward, und der Major Lange die angebotene Kapitulation abschlug, sagten brave Gemeine: `daß ist recht, dreymal ist preußische Losung, ehe sie nicht zum drittenmale gestürmt, und wir uns tapfer gewehret haben, müssen wir uns nicht ergeben ${ }^{148}$."

Auch der Feldwebel Liebler verweist auf drei Angriffe, an denen er sich in der Schlacht bei Prag beteiligt hat ${ }^{149}$.

So wenig Belege es für die Ausführung der Tat gibt, so wirksam war offensichtlich die Drohung. Es scheint sinnvoll, sie nicht nur unter dem repressiven

14.3 Kriegs- und Friedensbilder aus den Jahren 1754-1759. Nach dem Tagebuch des Leutnants Jakob Friedrich Lemcke 1738-1810. Hrsg. von R. Walz, Neudr.-der Ausg. 1909, in: Kriegs- und Friedensbilder 1725-1759. Mit einer Einl. von Hans Bleckwenn, Osnabrück 1971, S. 32-34; Prittwitz, "Ich bin ein Preuße ... (wie Anm. 85), S. 111 f.; Witzleben, Aus alten Parolebüchern (wie Anm. 56), S. 37; Unter Friedrich dem Großen (wie Anm. 80), S. 28-34; Lossow, Denkwürdigkeiten (wie Anm. 53), S. 26 f., 216.

144 Prittwitz, »Ich bin ein Preuße ...« (wie Anm. 85), S. 97. Barsewisch, Von Rossbach (wie Anm. 66), S. 78.

145 Berenhorst, Aus dem Nachlasse (wie Anm. 46), S. XVI; Kriegs- und Friedensbilder (wie Anm. 143), S. 28. Lemcke zeigt sich gänzlich unbeeindruckt von Mansteins schaurigem Ende. Berenhorst haßste ihn, verzichtete aber darauf, wie versprochen auf seinen Leichnam zu urinieren [sic!], weil er von Mansteins Tapferkeit beeindruckt war.

146 Unter Friedrich dem Großen (wie Anm. 80), S. $87 \mathrm{f}$.

147 Ebd., S. 90.

148 Küster, Bruchstück (wie Anm. 75), S. 189.

149 "Schreiben des Feldwebels Liebler. Im Lager bei Prag, den 7. Mai 1757 «, in: Briefe (wie Anm. 12), S. 47. 
Aspekt, sondern nach ihrer Wirkungsweise und Einbettung in das militärische System zu untersuchen. Die sehr lückenhaften Quellen zur Strafpraxis deuten an, daß Desertion im Kampf mit dem Tode bestraft wurde. Zugleich zeigt sich in der (Nicht-)Ahndung verschiedener Arten von Flucht eine realistische Sichtweise auf die Möglichkeiten der Soldaten und Offiziere ${ }^{150}$. Man wußte, daß ein "panisches Schrecken « jeden treffen konnte ${ }^{151}$. Man wußte aber genauso, daß die potentielle Bereitschaft, den Soldaten zu erstechen, ein rabiates, aber wirkungsvolles Mittel war, den Soldaten wieder zu sich zu bringen. Für den Soldaten war es Zwang und Überlebensstrategie zugleich. Panik war das Schlimmste, was einer Einheit im Kampf zustoßen konnte. Unabhängig von der realen Anwendung scheint es eine Toleranzzone im Verhalten der Offiziere gegeben zu haben. Soldaten mußten bis zu einem gewissen Grade ihre Pflicht tun. In bestimmten Situationen wurde toleriert, daß sie nicht mehr stehen bleiben konnten ${ }^{152}$. Hülsens Ausspruch über den "gemeinen Mann, der drei Treffen geschlagen hatte«, zeigt unabhängig vom Wahrheitsgehalt, daß dies als große Leistung angesehen wurde. Er selbst zeigt dies deutlich genug. Offenbar verschwand an dieser Grenze für den Offizier die Legitimation, den Soldaten von hinten zu erstechen. Dies könnte auch eine Erklärung für die Wut der von Liebler geschilderten österreichischen Verwundeten sein, die ihren Ärger verständlich macht. Über den erzwungenen (und als solchen höchst unüblichen) Schwur sind die Soldaten empört, weil er genau diese Toleranzzone außer Kraft setzt und der Offizier damit die Legitimation erhält, sie nach tapferer Gegenwehr durch Niedermachen am Rückzug zu hindern. Diese stillschweigende Ubereinkunft könnte auch erklären, warum die Drohung zumindest dazu beitrug, Männer im Gefecht zu halten, und gleichzeitig so wenig zur Anwendung kam. Zu Massenfluchten kam es auf seiten der preußischen Armee sehr selten.

Der zentrale Grund für die wenig oder nie vorkommende Ausführung des Befehls, einem Fliehenden den »Degen in die Rippen zu stoßen «, lag wahrscheinlich darin, daß Offiziere und Gemeine im Bataillon nicht nur einen gemeinsamen Kommunikationsraum hatten, sondern auch von kollektiven Stimmungen gemeinsam beeinflußt wurden. Offiziere waren an Massenfluchten genauso beteiligt wie Soldaten. So schreibt Friedrich II. an den Generalmajor von Kurssell im Lager von Prag im Juni 1757. Dieser wehrte sich gegen den Vorwurf, das Regiment habe in der Schlacht nicht standgehalten. Er sagt, »daß meine sämmtliche Capitaines und Subalternes sowohl bei der ersten Attaque, wo sie sich bis auf den allerletzten Mann distinguiret, wie auch bei der zweiten Canonade alles das gethan, was ehrliebende und brave Officiers zu thun schuldig sein«. Alle Offiziere hätten sich über »sein sehr schlechtes Verhalten « (des Kommandeurs) beschwert. Friedrich sieht die Sache anders: »Was beschuldigen Sie dann den Massow? Dann daß Sie alle gelaufen; habe ich mit meinen sichtbaren Augen zu meinem grossen Leidwesen gesehen ${ }^{153}$." Ein fliehender Offizier konnte keine fliehenden Soldaten niederstechen ${ }^{154}$.

150 Vgl. hier die bemerkenswerte Passage im Militärischen Testament Friedrichs II., daß die härtesten Strafen auf Nachlässigkeit im Wachdienst und Nichtbefolgung von Befehlen stehen, nicht aber auf »Feigheit», denn sie »läßt sich nicht anders bestrafen, als daß man solche Memmen mit Schimpf und Schande wegjagt«. Friedrich II., Das Militärische Testament von 1768, in: Militärische Schriften (wie Anm. 46), S. 237.

151 Möbius, Von Jast und Hitze (wie Anm. 4), S. 27 f.

152 Vgl. hierzu Showalter, Tactics (wie Anm. 19), S. 28 f.

153 Politische Correspondenz Friedrichs des Grossen (wie Anm. 62), Bd 15, S. 123.

154 Vgl. Prittwitz, »Ich bin ein Preuße ...« (wie Anm. 85), S. 95. 
Ein anderer Grund mag in der Angst vor Racheakten gelegen haben. Erkannten Soldaten eine Flucht als legitim an, würde ein Offizier mit Vergeltung seitens der Freunde und Kameraden der von ihm Erstochenen zu rechnen haben ${ }^{155}$. Hatte der entsprechende Offizier bei der nächsten Aktion das Pech, vor dem Peloton postiert zu werden, bot sich eine ausgezeichnete Gelegenheit, ihn unerkannt zu töten $^{156}$.

\section{Die Antwort der Soldaten}

Die Reaktionen der Soldaten auf die Beeinflussungsversuche der Offiziere bestand in den genannten Beispielen vor allem darin, im Sinne ihrer Vorgesetzten zu agieren. Dabei wird deutlich, daß die schreibenden Soldaten aller Ränge die positive Anknüpfung an gemeinsame Interessen dem bloßen Druck oder gar der Gewaltanwendung vorzogen. Die wenigen erhaltenen verbalen Äußerungen von Soldaten während des Gefechts sind zu lückenhaft, um aus ihnen auf generelle Verhaltensweisen schließen zu können. Dennoch ist angesichts des Fachpublikums der entsprechenden Literatur davon auszugehen, daß sie nicht als unmöglich oder völlig außerordentlich gesehen wurden. In jedem Fall deuten sie darauf hin, daß der "gemeine Mann« klare Vorstellungen von seinen eigenen und den Pflichten seiner Vorgesetzten hatte. Die beiden als harte Ausbilder bekannten Generäle »Mayring und Forcade « verloren in einem Gefecht zu Beginn des Siebenjährigen Krieges den Kopf.

"Die Soldaten wurden unwillig, daß sie solche Ausdrücke von einem General hörten, der in Berlin, wo er Gouverneur war, für einen Eisenfresser gehalten wurde; sie schrien also eben so laut: man muß die Feinde auf den Neumarkt schicken; dies ist ein Ort in Berlin, wohin Mayring die Soldaten in Arrest brin gen ließ ${ }^{157}$. «

Das weitgehende Ausbleiben von Strafe für die Flucht oder den Rückzug von Einheiten in Situationen, die durch die Pflichtvorstellungen der Männer nicht mehr abgedeckt waren, deutet zudem darauf hin, daß sie von den Vorgesetzten geteilt wurden oder wenigstens akzeptiert werden mußten, um allgemeinen Unmut zu vermeiden.

Barsewisch berichtet über den oben angeführten Angriff seiner Einheit in der Schlacht bei Leuthen, daß es den Offizieren gelang, die Soldaten bis zum ersten Schußwechsel durch Güte und Gewalt vom Vorstürmen abzubringen. Nach der ersten Salve ließen sie sich aber nicht mehr zurückhalten. »Unsere beherzten Soldaten hatten nun keine Geduld mehr, sondern liefen mit der größten Bravour und dem gefällten Gewehr auf den Feind zu, so daß wir bei der zweiten Salve bereits unter seinen Canonen waren [und die Württemberger aus ihren Stellungen vertrieben]. " Bemerkenswert ist, daß die Offiziere in dieser Situation nicht mehr versuchten, die Soldaten zurückzuhalten, sondern deren Drang nachgaben, die Ge-

155 Hans Friedrich von Flemming, Der vollkommene teutsche Soldat, Leipzig 1726, S. 286, Sp. 2.

156 Duffy, The Military Experience (wie Anm. 8), S. 213, S. 220.

157 Siehe Warnery, Feldzüge (wie Anm. 62), T. 1, S. 26. 
fahrenquelle durch einen schnellen Erfolg zu beseitigen. Offenbar wirkte der Erfolg des Regiments so stark auf den "gemeinen Mann«, daß eine spätere Aufforderung, sich ablösen zu lassen, von den Infanteristen mit den Worten quittiert wurde: "Wir müßten Hundsfötter sein, wann wir nun in das zweite Treffen gingen. Patronen her, Patronen her ${ }^{158 !}$ «

Umgekehrt verhielt es sich in den genannten Fällen von Massenfluchten. Besonders interessant ist hier die Anfangsphase der Schlacht bei Prag. Der erste preußische Infanterieangriff wurde von 14 Bataillonen auf dem linken Flügel ausgeführt. Nach dem Abschluß des preußischen Umgehungsmarsches sah der dort kommandierende Graf von Schwerin Eile geboten, da die Österreicher das Manöver bemerkt hatten und Truppen auf ihren rechten Flügel verlegten. Er hielt allerdings einige abgelassene Karpfenteiche für Wiesen und ließ seine Truppen einschwenken. Die Soldaten blieben zum Teil bis zur Taille im Morast stecken und mußten sich schon unter dem Feuer der österreichischen Kanonen formieren. Die preußische Artillerie hingegen war zum größten Teil in Unter-Poczernitz steckengeblieben, so daß nur wenige Kanonen den folgenden Angriff unterstützen konnten.

"[Schwerin und Winterfeldt hatten befohlen], daß die Infanterie nicht feuern, sondern mit gefälltem Bajonette in den Feind eindringen sollte; da aber dieselbe in dieser Absicht, und um so eher aus der Kanonade zu kommen, mit einem etwas zu starken Schritte avancirte, und dieserhalb sowohl, als wegen des ungünstigen Terrains die Linie nicht in der besten Ordnung blieb ${ }^{159}$."

Die Preußen bildeten hierbei keine zusammenhängende Linie. "Sie befanden sich teils in der Staffel rechts rückwärts, teils sogar hintereinander, so daß sie von den Österreichern später als 2 . Treffen betrachtet wurden ${ }^{160}$ " « Hier zeigte sich die in der Ausbildung angenommene "Hitze" beim Angriff. Erwartungsgemäß beschleunigten die Truppen ihr Tempo, um schneller durch das gegnerische Feuer zu gelangen. Während die preußischen Bataillone solchermaßen vorrückten, wurden sie von der schweren österreichischen Artillerie beschossen. Zugleich kamen auch weitere österreichische Verstärkungen an. Deren Manöver beim Formieren einer Linie wurden von Winterfeldt offenbar als beginnender Rückzug wahrgenommen $^{161}$. Die preußischen Grenadiere und Musketiere schätzten die Lage anders ein. Viele ihrer Kameraden waren bereits durch die Vollkugeln und Kartätschen der schweren Artillerie getötet oder verletzt worden. Auf eine Entfernung von 200 bis 300 Schritt begannen die Österreicher dann mit ihren Gewehren und Bataillonsgeschützen zu schießen. Den Soldaten schien ein weiteres Vorrücken ohne Feuer nun nicht mehr eine Verminderung der Gefahr darzustellen, sondern eine Erhöhung derselben,

"folglich die vorhabende Attaque mit dem Bajonette wegfiel, und die unsrigen gleichfalls zu feuern anfiengen; allein dieses geschahe nicht lange mehr im Avanciren; denn da unsere Infanterie nicht in der besten Ordnung war, der Feind aber in seinem Posten sehr wohl rangiret stand, so continuirte dieses Feuer nur noch auf der Stelle, und ohne daß unserer Seits Terrain gewonnen wurde, und da wir besonders durch das feindliche Kartätschen-Feuer viel litten, das Regiment Fouqué auf eine Batterie von 14 Kanonen traf, und sehr viel Leu-

158 Barsewisch, Von Rossbach (wie Anm. 66), S. 37-41.

159 Gaudi, Abschriften (wie Anm. 64), S. 76.

160 Hoen, Die Schlacht bei Prag (wie Anm. 91), H. 3, S. 387.

161 Winterfeldt, Relation von der Bataille bei Prag (wie Anm. 5), S. 436. 
te durch dieses Feuer verlohr, so wich dieses Regiment zuerst, und das war das Zeichen für das von Schwerin, so wie für die Grenadier-Bataillons Oestereich, Waldow, Möllendorf, Kahlden, Plötz und Burgsdorff, welche den linken Flügel der Infanterie ausmachten, und gleich darauf dem Feinde den Rücken zukehrten und zerstreuet zurückgiengen ${ }^{162}$."

Solange sich die Soldaten eine Chance ausrechnen konnten, den Gegner zurückzuwerfen und dadurch ihre Bedrohung zu mindern, hatte das Beispiel der vor den Männern reitenden Kommandeure sie ermutigt. Mit dem Einsatz aller verfügbaren Feuerwaffen auf seiten der Österreicher änderte sich dies. Zum einen waren bereits die Generale Fouqué und Kurssell schwer verwundet, und dem bei den Soldaten beliebten Winterfeldt durchschlug kurze Zeit später eine Kugel den Hals. Die Preußen hielten an und begannen von sich aus zu schießen. Offenbar hatte das Gefühl der Hilflosigkeit angesichts des verheerenden feindlichen Feuers gegenüber der »Hitze« des Angriffs die Oberhand gewonnen. Als nun Offiziere versuchten, die Truppen gemäß dem Befehl weiter voranzuführen, vergrößerte dies nur die Unordnung. "Die Bataillone ballten sich um ihre Fahnen, verloren dadurch an Feuerkraft und boten massige Ziele, in welche die Artillerie breite Lücken riß ${ }^{163}$.《 $\mathrm{Ob}$ hier die feuernden Soldaten oder die vorwärts treibenden Offiziere die realistischere Einschätzung hatten, ist wohl nicht mehr festzustellen. Wichtig ist in unserem Zusammenhang, daß die Befehle der Offiziere mit der Einschätzung der Soldaten in einer Weise kollidierten, die eine erfolgreiche Kommunikation unmöglich machte.

Interessant ist der Vergleich mit der von Barsewisch geschilderten Attacke in der Schlacht bei Leuthen. In beiden Fällen wollen die Soldaten schnell an den Gegner kommen, um die Gefahr für das eigene Leben zu verringern. In beiden Fällen setzen sich die »Gemeinen « am Ende durch. Aufgrund der günstigeren Situation und der geglückten Kommunikation des Verlangens der Soldaten an ihre Oberen nach dem schnellen Angriff haben die Preußen bei Leuthen Erfolg. Bei Prag hingegen versuchen die Offiziere den Befehl zum Bajonettangriff auszuführen, kümmern sich nicht um die Abstimmung mit den Füßen ihrer Männer und verschlimmern die Lage dadurch noch. Dabei spielte die Situation eine nicht unwichtige Rolle. Angesichts der sich verstärkenden Österreicher war Eile geboten. Hinzu kam erschwerend die Anweisung von seiten des gesamten Oberkommandos, den Gegner ohne zu schießen anzugreifen. Damit wurde versucht, mittels einer einseitigen Kommunikation von oben nach unten auf das Verhalten der Soldaten einzuwirken. Die offenbar notwendige Flexibilität war somit ausgeschaltet und es kam zur Katastrophe.

In eine ähnliche Richtung deutet der Bericht des Leutnants Lemcke aus der Schlacht bei Kai/Paltzig, als er mit den Überlebenden seines Pelotons versucht, eine russische Batterie von 12 Kanonen zu erobern. Seine Männer suchen jedoch Deckung hinter Bäumen und schießen von dort auf die Russen. Der junge Leutnant schlägt seinen Degen auf den Rücken der Soldaten krumm, die sich aber nicht vorwärts treiben lassen. Als Lemcke dann der Fuß von einer Kanonenkugel abgerissen wird, fliehen seine Leute, bald gefolgt von zwei russischen Bataillonen ${ }^{164}$. 
Lemckes Vorhaben, einen zahlenmäßig weit überlegenen Feind frontal anzugreifen, ist gelinde gesagt verwegen. Seine Männer können sich nur zu leicht ausrechnen, daß das Vorgehen Tod oder Verstümmelung bedeuten wird. Daß sie nach seiner Verwundung das Weite suchen, ist angesichts des folgenden Vormarsches ausgeruhter und überlegener russischer Einheiten nicht weiter verwunderlich. Es ist gerade seine Verkennung der Situation und das Fehlen einer gemeinsamen Kommunikationsbasis, die erst zur Gewaltanwendung durch Lemcke und dann zur Flucht der Musketiere führt ${ }^{165}$.

Erweist sich in dem eben genannten Beispiel die Flucht der Soldaten als einzige Lösung, wenn sie nicht sinnlos getötet werden wollten, konnten Soldaten auch versuchen sich dem Kampf zu entziehen. Friedrich II. beschwert sich in der Instruction für die Generalmajors von der Infanterie von $1759^{166}$, daß Soldaten ihre Patronen wegwerfen, um so schneller zum Patronenfassen nach hinten kommandiert zu werden. Eventuell geschah dies kollektiv, um die Einheit aus der ersten Linie zu bringen. Das bereits angeführte Beispiel Küsters, der bei Hochkirch von einem Soldaten mit dem Degen beworfen wird, weil er ihn und seine Kameraden aus dem vermeintlich sicheren Versteck in den Kochlöchern wieder in die Feuerlinie bringen will, zeigt, daß die individuelle Flucht aus der Gefahrenzone bis zum offenen Widerstand reichen konnte. Das Beispiel zeigt allerdings auch, wie wenig genormt das Bewußtsein und Verhalten der "Gemeinen " war.

In der Schlacht bei Kolin war das Regiment Bevern, dem auch der spätere Leutnant von Prittwitz angehörte, von österreichischer Kavallerie überritten worden.

"Auf dem ganzen Platze lagen lauter Tote, teils in Wirklichkeit, teils aber auch nur dem Scheine nach, denn da die Burschen sahen, daß sie nichts mehr gegen den Feind ausrichten konnte, warfen sie die Gewehre weg und fielen zur Erde. [...] Als ich mich zu stark bewegte und das Aufstehen im Schilde führte, hörte ich eine leiste Stimme des Inhalts: >Bleiben Sie liegen, bleiben Sie liegen.< Der Mann, der dieses sagte, ein bejahrter Unteroffizier, welcher neben mir lag, verstand das Ding besser als ein neugebackener Fähnrich, der büßen mußte dafür, daß er den guten Rat nicht annahm ${ }^{167 . "}$

Hier nutzen die Soldaten ihre militärische Kompetenz, um in einer aussichtslosen Lage ihr Leben zu retten. Prittwitz' Verweis auf die mangelnde eigene Erfahrung deutet zudem darauf hin, daß er dieses Verhalten für angebracht hielt.

\section{Resümee}

Die Befunde legen eine Synthese der Positionen in der Forschung nahe. In der Ausbildung standen Befehl und Gehorsam im Mittelpunkt. Diese sollten einen möglichst reibungslosen Ablauf der Bewegungen des Bataillons gewährleisten. Die verbale Ebene der Kommunikation bestand aus taktischen Befehlen, Tadel und Flüchen und eventuell Lob. Zwang wurde auf die Soldaten meist durch die Drohung mit

165 Alternative Diskussion der Passage in: Sikora, Disziplin (wie Anm. 8), S. 166 f.

166 Friedrich II., Instruction für die Generalmajors von der Infanterie vom 12. 2. 1759 (wie Anm. 44), S. 273.

167 Prittwitz, "Ich bin ein Preuße ..." (wie Anm. 85), S. 60. 
dem Stock und das Schlagen mit dem Stock ausgeübt. Sofern der Musketier nicht vorhatte, so schnell wie möglich zu desertieren, konnte das Überlebensinteresse der Soldaten eine gemeinsame Kommunikationsbasis mit den ausbildenden Offizieren darstellen, da eine gute Ausbildung die Chancen erhöhte, unversehrt aus dem Kampf zu kommen.

Während des Kampfes fand die Kommunikation in einem Dreieck zwischen den höheren Befehlshabern, den Linienoffizieren und den Soldaten statt. Die Strategie der Offiziere ist auf die Umsetzung übergeordneter Befehle und die Vermehrung von Ehre und Gut durch militärischen Erfolg gerichtet. Bei den "Gemeinen« steht hingegen ein professionell verstandenes Uberlebensinteresse im Mittelpunkt der Überlegungen. Es kann von einem mit den obrigkeitlichen Vorgaben übereinstimmenden Erfolgsinteresse geprägt sein, aber auch in der individuellen oder kollektiven Entfernung vom Kampfplatz bestehen oder in offenen Widerstand münden. Prägend für den Offizier scheinen die verbale und symbolische Kommunikation durch vorbildhaftes Verhalten oder Drohungen bis hin zur Gewaltanwendung bestanden $\mathrm{zu}$ haben.

Aufgabe der Offiziere scheint vor allem die professionelle Anleitung und Betreuung der Soldaten durch gutes Zureden gewesen zu sein. Zudem mußten Offiziere aller Ränge bereit sein, durch persönliches Beispiel ihre Untergebenen anzuspornen. Demgegenüber scheint die Anwendung von Gewalt vor allem den Charakter einer Drohkulisse gehabt zu haben. Schläge und Beschimpfungen sind dokumentiert, das angeordnete Erstechen von Flüchtigen ist jedoch in der vorliegenden Literatur nicht nachzuweisen. Daß entsprechende Anordnungen kein Spezifikum der preußischen Armee oder des Zeitalters der stehenden Söldnerheere waren, scheint dafür zu sprechen, daß entsprechende Drohungen weniger auf mangelhafte Motivation seitens der Soldaten zurückzuführen waren als auf den Umstand, daß die Todesangst auch bei motivierten und erfahrenen Soldaten zu Panikreaktionen führen konnte. Die rekonstruierbare verbale Kommunikation zwischen Offizieren und Soldaten spricht immer wieder Themenkomplexe an, die mit den Bedürfnissen der Soldaten korrespondieren: Überleben, göttliche Belohnung für pflichtgemäßes Verhalten als "getreuer Krieges Knecht« und Vermehrung der Ehre.

Entgegen dem Diktum Friedrichs II. deuten die vorliegenden Befunde darauf hin, daß die Armee im Kampf nicht wie eine »Maschine funktionierte. Die Einschätzungen und Entscheidungen der einfachen Soldaten konnten eine entscheidende Rolle spielen und waren durch Gewaltanwendung nur in begrenztem Maße zu beeinflussen. Voraussetzung einer erfolgreichen Kommunikation war nicht die Durchsetzung von Befehlen übergeordneter Kommandeure um jeden Preis durch Gewalt und Drohungen, sondern das flexible Reagieren der Offiziere auf die Einschätzungen und Aktionen der »Gemeinen«. Gelang dies nicht, konnte es zum Zusammenbruch und zur kollektiven Flucht der Einheit kommen. Dann erwiesen sich auch »Degen, Sponton oder Kurz-Gewehr« im Rücken der Musketiere als wirkungslos. 


\section{Abstract}

The article dwells on the question how officers and private soldiers of the Prussian Infantry communicated in battle during the Seven-Years'-War. While the soldiers were exercised on the drill-square communication was mainly one-sided, the officer giving orders and the soldier obeying. Verbal abuses and corporal punishment with the (in)famous "stick " seem to have been on the order of the day. Yet a common basis for effective communication of military skill consisted in the soldiers' desire to maximize his chance to survive in combat.

In battle the pattern of communication changed. It consisted of a triangle formed by superior officers, the officers and NCOs of the line and the common soldiers. The officers not only had to communicate orders but to encourage the soldiers by "good words « and example. It seems that this kind of encouragement was more important than outright force, which the officers were ordered to apply when soldiers were about to flee. An analysis of the "good words « shows that these correspond to the common soldier's professional strategies of survival, their religious faith and sense of honour. When this common basis disappeared, force became useless and the unit was likely to break up. 


\section{Volksgemeinschaft oder Volksstaat}

\section{Steffen Bruendel Volksgemeinschaft oder Volksstaat Die "Ideen von 1914" und die Neuordnung Deutschlands im Ersten Weltkrieg}

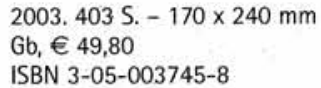

Der Autor leistet mit seiner Untersuchung einen grundlegenden, methodisch wie sachlich originellen Beitrag zu einer modernen Geschichte politischer Ideen, in deren Mittelpunkt die soziale Prägekraft kollektiv geteilter Wertvorstellungen steht. Dabei kann er deutlich machen, da $B$ das Thema der "Ideen von 1914" noch keineswegs hinreichend erforscht ist. Statt der eingespielten Ideologiekritik etablierter Deutungskonventionen, derzufolge die "Ideen von 1914" nur Ausdruck nationaler Verirrung oder eines spezifisch deutschen Hangs zu diffuser Sozialromantik seien, rekonstruiert der Autor den rationalen Gehalt dieser Ideen und kommt zu überraschenden Einsichten, die in den historischen Kulturwissenschaften insgesamt Diskussionen provozieren dürften. So kann er $u$. a. nachweisen, daß für die deutschen Gelehrten trotz des immer wieder behaupteten Primats der Außenpolitik innenpolitische Fragen im Vordergrund standen. In ideengeschichtlicher Hinsicht stellt der Systembruch von 1918/19 keineswegs eine tiefergehende Zäsur dar. Sowohl wichtige Inhalte der von antirepublikanischen Intellektuellen in den 20er Jahren entwickelten Sozialutopien als auch die entscheidenden Grundlagen der republikanisch-demokratischen Neuordnung von 1918/19 wurden bereits im Ersten Weltkrieg formuliert. Wenngleich der Autor die Utopie eines mnationalen Sozialismus" als Kernelement der "Ideen von 1914" herausarbeitet, konstatiert er keinerlei prädestinatorische Festlegung des weiteren Verlaufs der deutschen Geschichte. Der entscheidende Effekt der ideenpolitischen Debatte liegt für inn darin, die alte monarchische Ordnung delegitimiert und neuen Legitimitätsverheißungen zum Durchbruch verholfen zu haben. Die Komplexität der historischen Prozesse in den ersten beiden Jahrzehnten des 20. Jahrhunderts läßt sich nun einmal nicht auf die "Vorgeschichte" zu 1933 reduzieren. Das Buch von Steffen Bruendel wird insofern zur Revision etablierter Deutungsschemata zwingen. 